This item was submitted to Loughborough's Research Repository by the author.

Items in Figshare are protected by copyright, with all rights reserved, unless otherwise indicated.

\title{
ICT as a general-purpose technology: The productivity of ICT in the United States revisited
}

PLEASE CITE THE PUBLISHED VERSION

http://dx.doi.org/10.1016/j.infoecopol.2016.05.001

\section{PUBLISHER}

(C) Elsevier

\section{VERSION}

AM (Accepted Manuscript)

\section{PUBLISHER STATEMENT}

This work is made available according to the conditions of the Creative Commons Attribution-NonCommercialNoDerivatives 4.0 International (CC BY-NC-ND 4.0) licence. Full details of this licence are available at: https://creativecommons.org/licenses/by-nc-nd/4.0/

\section{LICENCE}

CC BY-NC-ND 4.0

\section{REPOSITORY RECORD}

Liao, Hailin, Bin Wang, Baibing Li, and Thomas G. Weyman-Jones. 2019. "ICT as a General-purpose Technology: The Productivity of ICT in the United States Revisited". figshare. https://hdl.handle.net/2134/21850. 


\section{ICT as a general-purpose technology:}

The productivity of ICT in the United States revisited

Hailin Liao ${ }^{\mathrm{a}, \mathrm{i}}$, Bin Wang ${ }^{\mathrm{b}}$, Baibing $\mathrm{Li}^{\mathrm{c}}$, Tom Weyman-Jones ${ }^{\mathrm{c}}$

${ }^{\mathrm{a}}$ Faculty of Business and Law

Coventry University

United Kingdom

${ }^{\mathrm{b}}$ Asian Infrastructure Investment Bank

P.R. China

${ }^{\mathrm{c}}$ School of Business and Economics

Loughborough University

United Kingdom 


\begin{abstract}
Researchers have long been puzzled by ICT’s (Information and Communication Technology) contributions towards (productivity) growth. This paper investigates and reveals the multi-facets of ICT productivity and the mechanism through which ICT affects productivity by bringing all the distinct streams of existing findings together. In particular, we develop a two-level frontier-efficiency model to examine how ICT's direct and indirect impact on different components of productivity is related to the economic growth in the US. Our empirical analysis has confirmed that ICT investment does contribute to productivity but not in the usual manner - we find a positive (but lagged) ICT effect on technological progress. We argue that for a positive ICT role on growth to actually take place, a period of negative relationship between productivity and ICT investment together with ICTusing sectors' capacity to learn from the embodied new technology was crucial. In addition, it took a learning period with appropriate complementary co-inventions for the new ICT-capital to become effective and its gains to be realized. Our findings provide solid, further empirical evidence to support ICT as a general purpose technology.
\end{abstract}

Keywords: Bayesian inference, General purpose technology, Information and communication technology, IT diffusion and adoption, Stochastic frontier analysis, Total factor productivity. 


\section{ICT as a general-purpose technology:}

\section{The productivity of ICT in the United States revisited}

\section{Introduction}

Many researchers attributed the impressive growth performance observed in the second half of the 1990s in the US to rapid productivity growth and linked it particularly to ICT (Information and Communication Technology) investment which rose at a rate nearly double that of the preceding years (e.g., Cardona et al. 2013 and the references therein; Vu, 2013). For instance, Jones (2002) pointed out that the growth in output per hour and in multifactor productivity in the US rose substantially in the period of 1995-98, returning about 50\% of the way back to the growth rates exhibited before 1973 . Most importantly, the increase in growth rates is partially associated with an increase in the use of IT, as this component of capital accumulation contributed only $0.1 \%$ points of growth before 1973 , but by the late 1990s, this contribution has risen to $0.8 \%$ points. Jorgenson et al. (2003) further shows that the growth rate of value added in the US has been raised by $1.85 \%$ when $1995-2000$ is compared to 1990-95, of which capital input contributes $1.02 \%$ to the post-1995 revival and a little more than half of this is due to the surge in IT investment; whilst faster growth in TFP (Total Factor Productivity) contributes $0.40 \%$ and labour input contributes the remaining $0.44 \%$ to the growth resurgence. These figures and subsequent studies show the importance of ICT for economic growth and hence a deeper understanding of the role played by ICT in the US can potentially benefit other countries.

A widely accepted argument is that the rapid technological progress in the production of ICT and the induced accumulation of ICT capital raised productivity growth. This so-called "ICT-centred story” (Oliner et al. 2008) highlights the increasing importance of ICT as a driver of rising 
productivity and economic growth through direct TFP increase in ICT-producing sectors and through capital deepening and labour productivity improvement in ICT-using sectors (e.g. Jorgenson et al. 2003, 2008; Oliner and Sichel 2000, 2002; Stiroh and Botsch, 2007; Inklaar et al. 2005). Despite this appealing argument, previous studies have also produced mixed findings on ICT's role in growth even with more rigorous analyses by subsequent researchers (for example, Gordon, 2000; Colecchia and Schreyer, 2002; Cardona et al. 2013).

Underlying the mixed results are three notable reasons. First, the majority of "ICT-centred story" papers consider the phenomenon within a neoclassical growth accounting framework and mainly at country level, treating ICT as an additional input on top of normal physical and human capital, but largely ignoring the possible diffusion effect created by ICT investment on $\mathrm{TFP}^{1}$. In other words, standard neoclassical growth theory states that the use of ICT can boost labour productivity in ICTusing sectors, but does not change TFP in sectors that only use but do not produce ICT. In this end, there is no reason to expect acceleration in the pace of TFP growth outside of ICT production. Among the most relevant and frequent findings of this line of research, we note limited relevant importance of ICT spillovers on TFP in various European countries, which is in sharp contrast to their effect in the US economy ${ }^{2}$.

Secondly, it has long been a research hypothesis in the literature that ICT is a general purpose technology (GPT), which is usually characterized as an enabling technology that induces further innovations and is adopted in a wide scope of sectors of an economy. Clearly, even though some

\footnotetext{
${ }^{1}$ This is because the traditional index number approach adopted in the existing empirical studies does not allow an unequivocal appraisal of the indirect effect of ICT on TFP, which has been recognized at the theoretical level by Helpman (1998).

${ }^{2}$ In contrast to the US, studies by Colecchia and Schreyer (2002) found that the ICT capital deepening contribution to aggregate labour productivity growth in Europe was only half of that in the US, mainly due to the much lower ICT investment levels in Europe, and the increase in ICT-investment, though, was not accompanied by a faster growth of TFP. To what extent this is due to a smaller ICT producing sector in Europe or to less productive ICT use is still not known.
} 
evidence of ICT spillovers in the US can be observed, the productivity impact of ICT cannot be materialized until it reaches a critical mass of diffusion and experience. If ICT is indeed a GPT, then ICT-using sectors/firms learn from the embodied new technology with some "unobserved complementary co-invention” (Basu et al. 2003), and the resulting pace of technology adoption will be slower than is socially optimal. This so-called "ICT-related story" (Oliner et al. 2008) emphasizes the powerful connection between ICT and technology diffusion across sectors by seeking to establish the positive spillover effect of ICT on TFP in ICT-using industries. The contrast between these "ICTcentred" and "ICT-related" conceptualizations is illustrated in Figure 1, from which we can see clearly that one channel operates by treating ICT as an additional input which could be potentially substitutable for the other inputs, while the other treats ICT as a complementary component of the management environment. Recent review in Cardona et al. (2013) shows that although ICT displays many GPT characteristics further and stronger empirical evidence is necessary. For example, there is no direct empirical evidence to show that a real time lag exists in the earlier ICT payoff studies, possibly due to the limitations of the methodologies in defining the underlying production technology, and some studies employed arbitrary numbers of years as the "lagged" time before the positive payoff from ICT investment (Basu et al., 2001, 2003; Bryjolfsson and Hitt 1996). Hence, this represents an important research gap.

(Figure 1 is here)

Thirdly, the mechanism through which ICT affects productivity growth, especially through efficiency enhancement, is not clearly explored. Traditional economic analyses of growth operate on the belief that there is full efficiency amongst firms, and the use of Solow's residual offers the ability 
of better measuring the productivity attributable to technology by using tangible outputs such as GDP, national wealth and revenue in the majority of earlier research. These output measures, however, might not capture the full contribution of ICT to an economy's productivity because the impact of ICT usage is generally considered to be wide ranging but intangible (Basu et al. 2007; Kleis et al. 2011). Alternative forms of productivity measurement, which provides more information about changes in technology are needed to better appraise the effectiveness of the use of ICT.

To address these research gaps, we will explore the multi-facets of ICT by adopting a frontierefficiency approach and examining how ICT's direct and indirect impact on different components of TFP is related to economic growth in the US over the period of 1977-2005. Our research therefore aims to answer questions on what contributions to productivity the ICT investment has made in the recent decades, in what way, and what might be the reasons that some ICT-using sectors underperformed on the basis of efficiency analysis. As a result, this paper provides further empirical evidence for ICT as a new type of GPT.

The approach used in this paper differs from previous studies in a number of ways. On the conceptual side, intensive studies have examined the relationship between ICT and productivity in an economic growth context, from the perspective of GPT nature of ICT and organizational reconstructing due to appropriate/complementary ICT-knowledge (Jorgensen et al. 2003, 2008; Oliner and Sichel, 2000, 2002; Basu et al. 2003; Brynjolfsson, 1993; Brynjolfsson et al. 1996, 2000, 2002). However, individually focusing on one aspect rather than simultaneously considering ICT's multifaceted impacts on productivity might yield mixed results - they can at the most uncover solely one aspect of ICT's impact and therefore might be conflicting to each other, or the overall result could show the combined/offset effects only with elusive findings arising from each individual aspect 
separately. By bringing the possible pieces of strands together into a single unified framework, it helps us unravel some puzzling phenomena reported in the published literature and therefore provides a better understanding of how various channels of ICT's impact work on productivity simultaneously.

On the methodology side, we develop a two-level stochastic frontier model which can accommodate both technological progress (TP) and technical efficiency change (TEC) ${ }^{3}$. Existing stochastic frontier methods have some fundamental limitations that make it very difficult to fully understand the roles that ICT plays. First, they normally impose a pre-specified structure on the frontiers (e.g. a log-linear structure) so they cannot detect complicated nonlinear structural changes of the frontiers. Secondly, they usually assume a constant effect in the statistical model for inefficiency, hence are unable to capture the dynamic evolution of technical efficiency and to explore the reasons for its changes. We conjecture that the pre-specified structure on the frontiers could be one of the reasons that the existing literature fails to reveal the unusual nature of ICT, when viewed as a new GPT that differs from the traditional inputs we are familiar with. Another direct consequence of a misspecified frontier structure is that the corresponding technical efficiency as part of TFP could be either under- or over-estimated, which will further lead to a biased analysis for efficiency. We show that the two-level stochastic frontier model developed in this paper does not impose any particular structure on the frontier functions, hence we are able to find the negative relationships between the productivity and ICT, if any, that were associated with the transition period. This new econometric model also leads to more accurately measured inefficiency for the production units of interest, which in turn provides us with an opportunity to investigate how technical efficiency evolves over time and also to

\footnotetext{
${ }^{3}$ There are other studies that address ICT productivity issues with stochastic frontier model. For instance, Becchetti et al. (2003).
} 
explore what factors affect it ${ }^{4}$.

In a nutshell, our empirical analysis has confirmed that ICT investment does contribute to the productivity change but not in the usual manner - we find a positive (but lagged) effect of ICT on TP and positive effect of ICT on TEC over time. Moreover, for a positive ICT role on growth to actually take place, our findings show that two points are crucial: the duration of a period of a negative relationship between productivity and ICT investment, and the capacity of the ICT-using sector to learn from the embodied new technology. For the latter, the software share of aggregate ICT investments and highly skilled labour can contribute to the enhancement of efficiency over time and thus the US industries have demonstrated the capacity to learn from the embodied new technology throughout the whole time span of the research. Our empirical results therefore suggest that an ICTcentred story might only reflect the ICT-driven growth in the post-1990 era when ICT plays a key role in productivity whilst the ICT-related story has better explained the transition period in the late-1980s. In addition, via breaking down the TFP into different components and establishing a relationship between technical efficiency changes and the proxies of organizational and other forms of intangible ICT investment (software share of aggregate ICT investments and highly skilled labour), we find some further evidence supporting the GPT theory.

This paper is structured as follows. Section 2 is devoted to the literature review. In Section 3, an econometric model with Bayesian inference is outlined. Section 4 describes the data which is followed by our empirical findings. The discussion is offered in Section 5 and the final section contains the conclusions.

\footnotetext{
${ }^{4}$ We would like to thank one reviewer's comment that not all the typical problems associated with ICT productivity estimation can be solved by using the two-stage stochastic frontier approach and by relaxing the pre-assumed functional form, e.g. quality mis-measurement of capital and labour, unobservable factors (intangible capital) and endogeneity issues, etc.
} 


\section{Literature Review}

This paper is at the confluence of three distinct streams of the ICT literature: (i) productivity of ICT in economic growth context; (ii) GPT nature of ICT in the context of spillover/externalities; and (iii) ICT infrastructure and absorptive capabilities in the context of efficiency improvement. In what follows, we describe how our work relates to each of these streams, and we also provide a brief review on methodical development at the end of this section.

\subsection{Productivity of ICT}

In order to organize the prior research on the relationship between ICT and recent economic growth, we follow the conceptual framework developed in Dedrick et al. (2003) to define the key variables, e.g. labour and capital to the production process and complementary factors of production that influence the production process, and to enable an assessment of the contribution of those inputs to outputs/outcomes (see Figure 1). A voluminous literature has provided abundant evidence on the positive effects of ICT on the structure of economies. For instance, many scholars attribute, at least in part, the increased shares of ICT investments in aggregate fixed capital formation to the resurgence of productivity worldwide during the late 1990s and the early 2000s. This line of argument is based on the ground that prices in ICT assets have declined relatively to those in non-ICT assets, which provide powerful incentives for the diffusion of ICT throughout the economy and the transition away from traditional non-ICT capital (see, Dewan and Kraemer 2000; Basu et al. 2003; Inklaar et al. 2005; among others).

From the perspective of empirical analysis, the literature applying the standard growth 
accounting framework usually sees the (labour) productivity effects of ICT as taking place in three stages. There are significant improvements in TFP in the industries producing ICT due to rapid technological progress, and the industries using ICT both undergo positively labour productivity improvement due to the induced accumulation of ICT capital that make workers more productive, and experience a boost in TFP growth as they introduce new modes of operation and continually improve the technology through phased product and process innovations. For the latter, such spillovers may result from the "re-organization of production" that ICT makes possible. For instance, Oliner and Sichel (2000) found that ICT capital deepening and industry productivity of the computer sector were responsible for two-thirds of the rise in average labour productivity during the late 1990s, and therefore confirmed the first two effects - TFP growth from ICT-producing sectors and ICT capital deepening - have played a major role in the US growth boom of the late 1990s. Jorgenson and Stiroh (2000) reached quite similar results although still questioned the extrapolation of TFP growth for long-term projection. Gordon (2000), however, was more sceptical about the contributions of ICT to aggregate growth and only supported the finding that the ICT-producing sector benefited from the TFP growth.

\subsection{ICT spillovers}

This paper is further related to two recent strands of the ICT-performance literature. The first one imports insights from knowledge spillover/externalities towards growth. More recent studies relying primarily on the use of industry sectoral data indicate that ICT is indeed playing a major role in the productivity of an economy and provide some evidence on the possibility of ICT spillover. For example, Jorgenson et al. (2003) show that TFP acceleration in the ICT-using service industries, in 
particular trade, finance and business services, appears to be important along with TFP growth in ICTgoods manufacturing, and the biggest contributors to aggregate ICT capital deepening are a limited number of these service industries as well. Basu et al. (2003) find in both US and UK a strong correlation between ICT use and industry TFP growth ${ }^{5}$. While a similar finding is obtained that TFP acceleration appears in finance and wholesale trade sectors, Inklaar et al. (2005) also finds a small increase in other ICT -using sectors.

On the one hand, all these findings suggest that the recent ICT “revolution” displays many GPT characteristics since computers and related equipment are used in most industries of the economy today, and ICTs have displayed a substantial level of technological dynamism spurring not only radical improvement in computational capacity but also a successive wave of new technologies, for example, internet and broadband, etc. Most important, ICT users respond to faster, more power computers and software by new ways of reorganizing firms and accumulating "complementary organizational capital” (Basu and Fernald, 2007). Thereby ICTs have clearly exhibited three key characteristic of GPTs identified by Bresnahan and Trajtenberg (1995), that is, commonness, technological dynamism and innovational complementarities with other forms of advancement.

On the other side, the spillover/externalities literature introduces a delay of ICT's impact on productivity/performance in the context of GPT perspective (Carlaw and Lipsey, 2002; 2006). Lipsey, Carlaw and Bekar (2005) offered a Structuralist-Evolutionary representation of the relationship between technology and the economy that goes beyond the production function and we incorporate this idea in Figure 1. Specifically, technology (that includes product, process and organisational

\footnotetext{
${ }^{5}$ The US results in Basu et al. (2003) indicate that the TFP acceleration was located primarily in ICT-using industries, which is consistent with that in Inklaar et al. (2005), and is positively correlated with industry "lagged" ICT investment but negatively correlated with current ICT investment for the period in the 1980s and early 1990s. Results using industry-level UK data are more mixed and suggest that contemporaneously rising ICT capital growth is positively, not negatively, correlated with the industry's TFP acceleration.
} 
technologies etc.) is embodied in the facilitating structure. Natural endowments are the only exogenous inputs that are fed into the productive system and are transformed by capital and labour into outputs, thus creating the performance variables. Without considering the complementary factors and "facilitating structure", the analysis of the impact of technology on performance will be boiled down to the usual framework of a production function, and it is the existence of potential mismatches between this facilitating structure and technology that might help to explain why some countries have more problems in adopting a GPT as compared to others, because changes in technology have no effect on performance until the elements of the facilitating structure have been adjusted to fit the new technologies.

Applying this concept in ICT, one may argue that these ICT spillover mechanisms may be 'lagged' because any benefits from ICT-producing sectors/firms via these mechanisms would be accumulated first by the ICT-using sectors/firms before they can be materialized. While most previous empirical studies in the ICT literature have been silent on this issue and have focused on ICT presence as a whole, there are a few exceptions. The time lag argument made by David (1990) proposed that IT would not have a measurable impact on productivity until it reached a critical mass of diffusion and experience. According to this hypothesis, (productivity) growth slowed temporally after 1973 "while the economy adapted its factories to the new production techniques associated with IT, and as workers learned to take advantage of the new technology”. The upsurge in productivity growth in the 1995 to 2000 period then reflects the successful widespread adoption of this new technology. Using a comparative analysis of the sluggish growth of productivity in the US prior to the 1920s, David (1990) argued that the resulting pace of technology adoption will be slower than is socially optimal where the capital goods embodying the new technology are competitively supplied and when there are 
significant knowledge spillovers among the firms in the supplying industry. This is quite consistent with one of explanations summarized by Brynjolfsson (1993) that management practices had not yet evolved to take advantage of the potential of the technology. There is, however, no direct empirical evidence to show that a real time lag exists in the earlier ICT payoff studies due to the methodological problem involved in defining the underlying production technology.

\subsection{ICT infrastructure and absorptive capabilities}

The associated second stream of the existing research examines the issue of ICT-performance nexus in the context of appropriate technology (Basu and Weil, 1998), and therefore depends on each production-unit’s own absorptive capabilities to the imported knowledge.

A serious weakness in the previous studies is that the absorptive capacity of host sectors/firms is treated with great simplicity. Absorptive capacity, represented by investments in knowledge infrastructure such as R\&D and/or human capital, can provide the basis of fundamental knowledge or technology necessary to assimilate and exploit external knowledge. When the rate of knowledge spillovers is treated as exogenous, however, one implicitly assumes that knowledge flows to the firm as some kind of "manna from heaven", and firms do not have to engage in any form of costly learning or search process in order to benefit from positive externalities. However, knowledge spillover effects are limited by domestic absorptive capacity. In the R\&D spillover literature, Cohen and Levinthal (1989) find empirical evidence strongly supporting the idea that the more R\&D-intensive firms are more successful in absorbing external R\&D spillovers.

The same logic applies in ICT spillovers. More specifically, while external knowledge, such as ICT generated from ICT-producing sectors/firms, can contribute to ICT-using production-units' 
knowledge, the sector/firm itself might still be unable to assimilate and utilize the external knowledge passively. Consistent with Cohen and Levinthal's (1989) argument that a firm's absorptive capacity determines the extent to which the firm can utilize the knowledge spillovers, we expect that the relationship between ICT and growth/productivity is also contingent upon the production-units' capacity to learn from the external. The greater the capacity to learn, the stronger the positive relationship discussed above. Following this logic, we will examine the moderating effects of two characteristics of production-units in terms of their ICT infrastructure - skill intensity and software share ${ }^{6}$, which have been highlighted in various prior researches on knowledge spillovers and absorptive capacity (e.g. Bresnahan et al. 2002; Caroli and van Reenen, 2001; Lin and Shao, 2006; Lin 2009; etc.). In doing so, we provide further evidence for ICT as GPT.

Before concluding this section, we contrast and highlight the differences between the empirical models used in the existing literature and the model proposed in this paper. In the literature, the approach of two-level model in stochastic frontier analysis can be traced back to the pioneering research in Koop et al. (2000) where a linear frontier model was assumed at the basic level describing the relationship between productivity and the corresponding inputs, whereas at the higher level, technical inefficiency was explained using a single binary variable, i.e. economic freedom, to indicate if an economic system under investigation is primarily free. However no time correlation of technical inefficiency was taken into account in Koop et al. (2000). In this paper we incorporate Tsionas’ (2006) two-level model where a dynamic inefficiency ${ }^{7}$ was considered, and have made some important

\footnotetext{
${ }^{6}$ Although there are several variables available, e.g. hardware, software and communication equipment, it is remarkable that the percentage contribution of software capital to output growth almost doubled from the second half of the 1980s to the second half of the 1990s in the US.

${ }^{7} \mathrm{~A}$ usual assumption in early applications is that the one-sided error is assumed independently and identically distributed across all production-units, but more recent studies have allowed that it depends on various production-unit's characteristics in the literature. One weakness of the earlier panel stochastic frontier models is that these inefficiencies are time invariant, e.g. Pitt and Lee 1981, Schmidt and Sickles, 1984. More recent studies have proposed alternative models
} 
changes. First, although the higher-level of the model used in this research has the same mathematical form as that in Tsionas (2006), we have used different environmental variables in our empirical analysis to tackle a different problem. In addition, the basic level of our model differs from that in both Koop et al. (2000) and Tsionas (2006): it relaxes the assumption of the frontier from the loglinear structure to a time-specific nonlinear form. This is essential because: (a) it enables us to detect any negative relationships between the output and inputs; and (b) it avoids the potential problem of mis-specifying the frontier structure, and hence produces more accurate measurements on efficiency. The latter forms a solid basis for any further analysis for efficiency.

\section{Econometric models and Bayesian statistical inference}

Methodologies used to analysing the impact of ICT on productivity can be classified into two broad categories: growth accounting and econometric estimations of production functions. The growth accounting approach estimates TFP using a non-parametric method assuming a theoretically based relationship between production elasticities and income share. However, it does not consider a number of specific factors influencing growth (Oliner et al., 2008). On the other hand, stochastic frontier analysis focuses on econometric estimations of production functions. It has an advantage that it avoids imposing a theoretically based relationship between production elasticities and income shares (Cardona et al. 2013). In this paper, we use a stochastic frontier approach.

\subsection{Empirical framework for econometric analysis}

that allow production-units' inefficiencies to change over time in some restrictive forms, e.g. Cornwell et al. (1990), Battese and Coelli (1992), Lee and Schmidt (1993). 
The recent review in Cardona et al. (2013) shows the importance of developing suitable methodologies in this area because many ambiguous results may be related to their methodological weaknesses.

As analysed before, the key issues of the impact of ICT on productivity growth lie in the GPT nature of ICT and the channels through which ICT affects productivity growth. In this regard, a twolevel stochastic frontier approach will be developed in this study as it can serve these research objectives very well by accommodating both TP and TEC in a single research framework (Koop et al. 2000).

Specifically, let random variable $y_{i t}$ denote the log-transformed output produced by productionunit $i$ (firm, industry, country, etc.) at time $t$, and $x_{i t}=\left[x_{i 1 t}, \ldots, x_{i k t}\right]^{T}$ the vector of the corresponding $k$ log-transformed inputs $(t=1, \ldots, T ; i=1, \ldots, N)$. In stochastic frontier analysis, the best practice technology for turning inputs $x_{i t}$ into output $y_{i t}$ is captured by the frontier function $f\left(x_{i t} ; \beta\right)$, where $\beta$ is the parameter vector to be estimated. In practice, actual output of a production-unit may fall below the maximum possible output characterized by the frontier function $f($.$) . The deviation of actual from$ maximum output, $u_{i t}$, is a measure of inefficiency. By taking into account the measurement error term $v_{i t}$, we can write the general frontier function model as:

$$
y_{i t}=f\left(x_{i t} ; \beta\right)-u_{i t}+v_{i t} \quad(t=1, \ldots, T ; i=1, \ldots, N) .
$$

Clearly the stochastic frontier model (1) decomposes the output $y_{i t}$ into three components: the ideal output $f\left(x_{i t} ; \beta\right)$, technical inefficiency $u_{i t}$, and traditional random error $v_{i t}$. Following the existing studies, it is assumed throughout this paper that the measurement errors $v_{i t}$ are independent of each other and follow a normal distribution with zero mean and standard deviation $\sigma$. In econometric modelling, technical inefficiency $u_{i t}$ is considered as a non-negative random variable that follows a certain statistical distribution such as exponential, gamma, or log-normal distribution (Koop et al., 
1999; Tsionas, 2006). In addition, $v_{i t}$ 's and $u_{i t}$ 's are assumed to be mutually independent as well as independent of $x_{i t}$ 's.

We start with some commonly used frontier models and show the potential problems/difficulties of these models when analysing ICT and economic growth. Then we propose a more general and sophisticated econometric model, and highlight how the issues of the productivity and ICT are investigated using the model developed in this research.

Following the existing empirical studies (e.g. Dewan and Kraemer, 2000), the first model we will consider is the log-linear production function in a Cobb-Douglas form which can be viewed as a linear approximation of the production function (1):

$$
y_{i t}=\beta_{0}+\sum_{j=1}^{k} x_{i j t} \beta_{j}-u_{i t}+v_{i t} \quad(t=1, \ldots, T ; i=1, \ldots, N),
$$

where, following Koop et al. (1999), $u_{i t}$ is assumed to follow a gamma distribution.

The time-invariant linear frontier model (2) has been widely used in the ICT and productivity context in the early applications (see, e.g. Cardona et al., 2013) due to the virtues of simplicity and empirical validations ${ }^{8}$. In general, however, this model is restrictive: it assumes fixed returns to scale in production and competitive product and factor markets, which leads to unitary elasticity of substitution among inputs. In addition, since parameters in equation (2) are assumed to be constant, the frontier does not change over time which is particularly restrictive for empirical exercises with a relative longer time span. As a consequence, TP cannot be measured via model (2).

An intermediate case would allow the intercept to be time-varying (therefore imposing Hicksneutral technical progress), but a more realistic assumption for stochastic frontier modelling is to specify a fully time-specific frontier below (see e.g. Koop et al., 1999):

$$
y_{i t}=\beta_{0 t}+\sum_{j=1}^{k} x_{i j t} \beta_{j t}-u_{i t}+v_{i t} \quad(t=1, \ldots, T ; i=1, \ldots, N),
$$

where $\beta_{j t}(t=1, \ldots, T ; j=0, \ldots, k)$ are time-specific parameters, varying from year to year. Following Koop et al. (1999), $u_{i t}$ is assumed to follow a gamma distribution.

In comparison with equation (2), model (3) has some advantages. First, TP can now be measured

\footnotetext{
${ }^{8}$ It is popular because it satisfies the regulatory conditions of quasi-concavity and monotonicity in production theory, and in the meantime it is simple because it is easy to apply and has special properties, e.g. homogeneous of degree and the powers of its production factors have special, interesting and important meanings, i.e. they mean the partial elasticities of output with respect to factors and also mean the factor shares of inputs (Lin and Shao 2006).
} 
via the shift of the frontier over time. In addition, the relaxation from fixed-coefficients to timespecific coefficients allows more accurate estimation of technical inefficiency $u_{i t}$. However, we note that many more parameters need to be estimated in model (3), whereas the number of observations at each time point, $N$, is usually not large in practice. This could cause difficulties in statistical inference if the frequentist's approach was used. We will return to this issue in Section 3.2.

In terms of addressing the issues associated with the impact of ICT on productivity growth, there are still two potential problems for models (2) and (3). First, we note that a pre-specified log-linear structure for the frontier is imposed. This seems reasonable for labour and non-ICT capital stock as their nature is well known in the literature and the log-linear structure works well in many applications. For the ICT capital as an additional input, however, this could be a problem because the previous studies have suggested that ICT has displayed many GPT characteristics and thus may have an unknown and possibly nonlinear relationship with the output (see, e.g. Basu et al. 2003). Clearly when the true frontier function is nonlinear, a log-linear structure like (2) or (3) may produce misleading results. This problem becomes crucial for addressing the issues of ICT as GPT because, as it will be seen later, a negative relationship is one of the key features. Therefore, it is of great importance to ensure that the model used in the research is able to detect any potential negative relationship between the ICT capital and the output ${ }^{9}$. This has motivated us to develop a new econometric model rather than using any existing ones.

Secondly, in the previous empirical studies of productivity analysis, very little attention has been paid to the modelling of technical inefficiency. In fact, most of previous empirical studies assume that technical inefficiency $u_{i t}$ is a non-negative random variable that follows a time-invariant distribution. As a result, the previous studies cannot reflect how technical inefficiency evolves over time and which factors may contribute to the enhancement of technical efficiency. The latter issue is of practical importance because it could provide evidence for the co-invention and re-organization theory which plays a central role in the ICT-related story (Basu et al. 2003). This in turn provides empirical evidence of ICT as GPT.

\footnotetext{
${ }^{9}$ The log-linear Cobb-Douglas specification assumes a strongly disposable production technology which does not permit time-varying or negative rates of return, but the potential for this variation is exactly what we wish to model and capture the richness of the ICT impacts which have been discussed in the literature.
} 
To address these issues, we have developed a two-level model in this research. At the basic level, a model for the frontier is specified as follows:

$$
y_{i t}=\sum_{j=1}^{k} f_{j t}\left(x_{i j t}\right)-u_{i t}+v_{i t} \quad(t=1, \ldots, T ; i=1, \ldots, N),
$$

where the assumption of linear relationship between the output and each of the inputs in model (3) is relaxed by a time-specific nonlinear frontier function, $f_{j t}().(t=1, \ldots, T ; j=1, \ldots, k)$, for which no particular structure is pre-imposed. The advantage of using time-specific non-linear frontier functions is that it allows us to detect and capture (if any) potential negative relationships between the output and the inputs, and thus to partially address the issues of ICT as GPT. It is worth noting that there are a few other empirical studies (such as Ketteni, 2009; Ketteni, et al. 2007) that share the idea that no pre-assumption on the relationship between the output and inputs should be imposed in order to investigate the real impact of that particular input on economic/productivity growth. In this way, the output elasticities of inputs or the like can be either positive or negative over time. In addition, since no particular structure is imposed for the frontier functions, technical inefficiency can be measured much more accurately.

Besides the TP reflected by the shift of the frontier functions, we also wish to understand how the technical (in)efficiency evolves over time. For this end, we introduce $M$ environmental variables, $z_{i j t}(j=1, \ldots, M)$, for each production unit $i$ at time $t$. The econometric model we use includes a higher level that is an autoregressive model with exogenous inputs (ARX). This higher-level model is used to investigate the dynamics of log of technical inefficiency, and the relationships between log of technical inefficiency and the $M$ environmental variables:

$$
\log u_{i t}=\rho \log u_{i t-1}+\sum_{j=1}^{M} z_{i j t} \gamma_{j}+\varepsilon_{i t} \quad(t=2, \ldots, T ; i=1, \ldots, N)
$$

and $\log u_{i 1}=\sum_{j=1}^{M} z_{i j 1} \gamma_{1 j}+\varepsilon_{i 1}$. The parameter $\rho$ in equation (5) reflects the time correlation of technical inefficiency, a measure of persistency of this important variable. The error terms in model (4)-(5), $v_{i t}$ and $\varepsilon_{i t}$, are assumed to be independent of each other, each having a normal distribution with zero mean and constant variance, i.e. $v_{i t} \sim N\left(0, \sigma^{2}\right)$ and $\varepsilon_{i t} \sim N\left(0, \omega^{2}\right)$ (for $t \geq 2$ ) and $\varepsilon_{i 1} \sim N\left(0, \omega_{1}^{2}\right)$. Equation (5) also allows technical inefficiency to be related to other environmental variables and hence allows researchers/policymakers to understand the behaviour of efficiency over 
time and to identify the sources of inefficiency accordingly upon which the relevant policies can be recommended. $\gamma_{j}(j=1, \ldots, k)$ are the corresponding coefficients of the environmental variables. As pointed out by Cardona et al. (2013), this would give clear and direct piece of evidence for the GPT theory.

In summary, the developed model in this paper, equations (4)-(5), assumes that there are several inputs that may contribute to the actual output of each production unit in a potentially nonlinear manner. In addition, the frontier functions of these inputs are linked via an additive model to characterise the output of interest. The inefficiency defined to be the deviation of the actual output from maximum output is further assumed to depend on its time-lagged value as well as some environment variables. This allows us to assess how the efficiency evolves over time and which factors affect the changes in efficiency.

\subsection{Statistical inference}

This subsection investigates statistical inference for the two-level model (4)-(5) developed in this paper. Overall, we use a non-parametric statistical method, cubic smoothing splines, to model the nonlinear frontier functions in equation (4) with a Bayesian approach for statistical inference since the model is time-specific and the sample size is relatively small at each time point (only 24 industries included in the empirical study). With the Bayesian approach, we are able to detect any possible negative relationships between the output and inputs, typical for the GPT nature of ICT investment, even if the sample size in each year is small. In contrast, the classical frequentist's approach relies on the asymptotic theory assuming that the sample size approaches positive infinity, which is not the case for our empirical analysis. Due to the complexity of the model, the statistical inference in this section is challenging.

\subsubsection{Modelling frontier functions}

Each time-specific function $f_{j t}().(t=1, \ldots, T ; j=1, \ldots, k)$ in equation (4) is modelled using natural cubic splines. An introduction to statistical modelling using cubic splines can be found in 
Green and Silverman (1994). Let $\mathbf{f}_{j t}=\left[f_{j t}\left(x_{1 j t}\right), \ldots, f_{j t}\left(x_{N j t}\right)\right]^{T}$ denote the vector of $f_{j t}($.$) evaluated$ at the observed input vector $\mathbf{x}_{j t}=\left[x_{1 j t}, \ldots, x_{N j t}\right]^{T}$. In the empirical analysis, the vector $\mathbf{f}_{j t}$ needs to be estimated using the collected data. On the basis of the estimated vector $\mathbf{f}_{j t}$, the entire nonlinear frontier function $f_{j t}($.$) can be worked out as a smooth curve (see Green and Silverman, 1994).$

\subsubsection{Likelihood}

In the Bayesian analysis, the output $y_{i t}$ is treated as observable variable, whereas the technical inefficiency $u_{i t}$ is treated as (unobserved) latent variable $(t=1, \ldots, T ; i=1, \ldots N)$. The complete-data in the analysis includes the measurements on both the output and technical inefficiency. Combining equations (4) and (5), the complete-data likelihood can be worked out as follows:

$$
\begin{aligned}
& p(\mathbf{y}, \mathbf{u} \mid \mathbf{X}, \mathbf{Z})=\left(2 \pi \sigma^{2}\right)^{-N T / 2} \exp \left\{-\sum_{t=1}^{T} \sum_{i=1}^{N}\left[y_{i t}-\sum_{j=1}^{k} f_{j t}\left(x_{i j t}\right)+u_{i t}\right]^{2} /\left(2 \sigma^{2}\right)\right\} \\
& \times\left(2 \pi \omega^{2}\right)^{-N(T-1) / 2} \exp \left\{-\sum_{t=2}^{T} \sum_{i=1}^{N}\left[\log u_{i t}-\sum_{j=1}^{k} z_{i j t} \gamma_{j}-\rho \log u_{i t-1}\right]^{2} /\left(2 \omega^{2}\right)\right\} / u_{i t} \\
& \times\left(2 \pi \omega_{1}^{2}\right)^{-N / 2} \exp \left\{-\sum_{i=1}^{N}\left[\log u_{i 1}-\sum_{j=1}^{k} z_{i j 1} \gamma_{j}\right]^{2} /\left(2 \omega_{1}^{2}\right)\right\} / u_{i 1},
\end{aligned}
$$

where $\mathbf{y}$ includes all $y_{i t} ; \mathbf{u}, \mathbf{X}$, and $\mathbf{Z}$ are defined similarly, each including $u_{i t}, x_{i j t}$ and $z_{i j t}$ respectively.

\subsubsection{Prior specification}

In the Bayesian analysis, the prior distribution for vector $\mathbf{f}_{j t}$ needs to be specified. We choose the following standard non-informative prior (see, e.g. Hastie and Tibshirani, 1990; Hajargasht, 2004):

$$
\mathbf{f}_{j t} \sim \mathrm{N}\left(0, \mathbf{K}^{-1} \tau_{j t}^{2}\right)
$$

where $\tau_{j t}$ is a hyper-parameter to be estimated. $\mathbf{K}$ is a given matrix; see Green and Silverman (1994, page 13) for the definition of $\mathbf{K}$.

Let $\boldsymbol{\theta}$ denote the vector of all other unknown parameters, including location parameters $\rho, \gamma_{j}$ and $\gamma_{1 j}(j=1, \ldots, M)$, and scale parameters $\tau_{j t}, \sigma, \omega$ and $\omega_{1}(t=1, \ldots, T ; j=1, \ldots k)$. The prior $p(\boldsymbol{\theta})$ for $\boldsymbol{\theta}$ is specified as a non-informative prior so that the subsequent inference is unaffected by information external to the collected data. For example, the prior for $\rho$ is specified as $p(\rho) \propto 1$ and the prior for $\sigma$ 
is specified as $p(\sigma) \propto 1 / \sigma$. The other priors are specified in a similar manner. They are assumed to be independent of each other a priori. Hence, the joint prior distribution is $p(\boldsymbol{\theta}) \prod_{t=1}^{T} \prod_{j=1}^{k} p\left(\mathbf{f}_{j t}\right)$.

\subsubsection{The posterior distribution}

Applying Bayes's rule to pool the information contained in the likelihood and the joint prior distribution yields the following complete-data posterior distribution:

$$
q\left(\boldsymbol{\theta}, \mathbf{f}_{j t}, \text { for all } j \text { and } t \mid \mathbf{y}, \mathbf{u}, \mathbf{X}, \mathbf{Z}\right) \propto p(\mathbf{y}, \mathbf{u} \mid \mathbf{X}, \mathbf{Z}) p(\boldsymbol{\theta}) \prod_{t=1}^{T} \prod_{j=1}^{k} p\left(\mathbf{f}_{j t}\right) .
$$

In theory all required information for statistical inference for the frontier function $f_{j t}().(t=$ $1, \ldots, T ; j=1, \ldots, k)$ and parameter vector $\boldsymbol{\theta}$ is contained in the above posterior. For the problem considered in this paper, however, it is not analytically tractable so we have to use a numerical approach to extracting the relevant information about them. This is discussed in the next subsection.

\subsubsection{Markov chain Monte Carlo simulation}

On the basis of the above complete-data posterior distribution, statistical inference can be drawn using the Markov chain Monte Carlo method. The algorithm used in this research is mainly based on the data augmentation method developed in Tsionas (2006). Specifically, the posterior distribution is simulated in the empirical analysis using an iterative procedure that consists of two alternating steps:

(i) Posterior-step: for given values of the latent variable $u_{i t}(t=1, \ldots, T ; i=1, \ldots N)$, simulate the frontier functions $\mathbf{f}_{j t}(t=1, \ldots, T ; j=1, \ldots k)$, and the parameter vector $\boldsymbol{\theta}$;

(ii) Imputation-step: for the given frontier functions $\mathbf{f}_{j t}(t=1, \ldots, T ; j=1, \ldots k)$, and the parameter vector $\boldsymbol{\theta}$, simulate the values of the latent variable $u_{i t}(t=1, \ldots, T ; i=1, \ldots N)$.

For Imputation-step, we can use the Metropolis-Hastings algorithm to simulate the values for the latent variable $u_{i t}(t=1, \ldots, T ; i=1, \ldots N)$. On the other hand, it can be shown by some algebra that the conditional posterior distributions of $\mathbf{f}_{j t}$ and each of the location parameters in vector $\boldsymbol{\theta}$ are normal, and the conditional posterior distribution of each scale parameter is an inverse gamma distribution. Hence, the Gibbs sampling method can be used for the Posterior-step.

To check the convergence of the MCMC simulation, we followed a commonly used method in 
statistics and econometrics by checking the R-value during the process of iterations; see Gelman, et al. (2014) for details. The number of iterations in the simulation of the empirical analysis was set as 20,000, where the first 10,000 iterations were treated as burn-in period and all the draws were discarded. The reported results were based on the remaining 10,000 draws. The estimated parameters were taken as the corresponding posterior means, and the performances of the estimates were measured by the posterior standard deviations.

\section{$4 \quad$ Data and main findings}

\subsection{Data}

The empirical analysis for the estimation and decomposition of TFP is based on the EU-KLEMS database $^{10}$. The EU-KLEMS database is the result of a research project performed by a consortium of 14 European institutions, funded by the European Commission. The database contains observations on output (Gross Output and Value-Added) and input (Capital - decomposed into ICT and non-ICT related capital, Labour - decomposed into high-, medium- and low-skilled labour, Energy, Materials, and Services) for 27 EU member countries, plus the US and Japan. Data are disaggregated at NACE Rev. 1 classification level. A distinguishing feature of the EU-KLEMS database is that a single method of estimation of capital, both ICT and non-ICT related, is used.

The raw data series used in this paper are value added, real gross fixed capital stocks of ICT and non-ICT assets, total hours worked by persons engaged, highly skilled labour shares in total hours and software shares in ICT assets. The sample consists of a balanced panel of annual time-series data for 24 ICT-using industries ${ }^{11}$ over the period 1977-2005 in the US. The reason for using data from 1977 onwards is that computers played a limited role in ICT-usage before 1977 and ignorance of data before 1977 should have no or neglectable effect on the conclusions. A summary of descriptive statistics is tabulated in Table 1 for the sample used in this paper.

(Table 1 is here)

\footnotetext{
${ }^{10}$ A detailed description of the dataset is provided in O’Mahony et al. (2009) and Timmer et al. (2007).

${ }^{11}$ The 24 industries and their corresponding SIC classification can be found in Appendix.
} 


\subsection{Main findings}

The frontier approach to decomposing the productivity growth in a macro-economic context into components due to efficiency change and technical change provides a platform for a straightforward and simple economic interpretation for output growth: (a) a country/industry/firm can be less efficient in the use of inputs therefore operates within the frontier, and "catches up" to the frontier over time represented as efficiency gains; and (b) the frontier itself can shift over time indicating technical progress. Consequently, different policy inferences can be drawn from different sources of variation in productivity growth as a high rate of TP can coexist with deteriorating technical efficiency whilst relatively low rates of TP can also coexist with improving technical efficiency. Bearing this mind we will focus on the estimation of the underlying production frontier and the analyses of both direct and indirect role of ICT investment on productivity with an aim to addressing the following questions:

- Is the ICT-centred story still the right explanation for the resurgence in productivity growth in the US over the time period of 1977-2005?

- $\quad$ Does the adoption of ICT-knowledge require organizational change or the like as suggested by the ICT-related story?

The answers to these two research questions will provide us a better understanding about the role that ICT plays in economic growth and hence evidence of ICT as GPT.

We start the exposition with some commonly used frontier models, and then relax the unrealistic assumptions step by step. Potential problems/difficulties of those restrictive models when analysing ICT and economic growth will be analysed so as to compare with results obtained from our proposed two-level frontier model. As it will be seen later this section, we find that ICT does contribute to the 
productivity but not in the usual manner: (i) the positive (but lagged) effect of ICT on TP is found due to GPT nature of ICT; and (ii) the positive effect of ICT on TEC over time suggests that a significant component of the ICT value is its ability to enable complementary organizational investments and the firm/production-unit’s ability to absorb the embodied new-technology.

\subsubsection{Estimation of stochastic production frontier}

For the problem of ICT productivity, the ideal output $f\left(x_{i t} ; \beta\right)$ is characterized by a technological transformation process in which the technological advance is viewed as a result of ICT production in the ICT-producing sectors. In this paper we consider three inputs in particular, $x_{i 1 t}, x_{i 2 t}$ and $x_{i 3 t}$, defined to be the natural logarithms of non-ICT capital stock, ICT capital stock and labour in period $t$ in industry $i$. The corresponding output $y_{i t}$ is taken as the natural logarithm of value added.

We first start our exposition with the results estimated from the model assuming a time-invariant log-linear production function, i.e. equation (2), as shown in Table 2.

\section{(Table 2 is here)}

It can be seen from Table 2 that the estimated output elasticities of inputs are all positive and significant, with the value of $0.18,0.16$ and 0.60 for output elasticities of non-ICT capital, ICT capital and labour, respectively. The results are generally in line with many previous studies obtained using a log-linear production function. For instance, Dewan and Kraemer (2000), using an inter-country Cobb-Douglas function relating IT and non-IT inputs to GDP outputs for 36 countries over the period 1985-1993, found that IT investments contribute to improvement in the national productivity of the developed countries ${ }^{12}$. Their corresponding output elasticities were $0.160,0.057$ and 0.823 , respectively. The estimated output elasticity of the non-ICT capital of 0.160 in Dewan and Kraemer (2000) is similar to ours of 0.18 in Table 2. However, their estimated output elasticity of ICT capital

\footnotetext{
${ }^{12}$ But the returns from IT capital investments are not statistically significant for the developing countries in Dewan and Kraemer (2000).
} 
of 0.057 was relatively low and the output elasticity of labour was relatively high. Presumably this was due to the fact that their estimate was the results averaged over a number of countries, whereas the results displayed in Table 2 are for the US only. We also note that McGuckin and Stiroh (2002) undertook a study at industry level for the US and they obtained an estimate of 0.17 for the elasticity of ICT capital which was close to our result of 0.16 .

However, as mentioned earlier, the time-invariant linear model (2) can be misleading for a relatively long span of time as it implicitly assumes that the frontier is fixed over time. To take this into account, we used a time-specific log-linear production frontier, e.g. equation (3), to analyse the data. The results are displayed in Table 3.

(Table 3 is here)

The analysis using a time-specific log-linear production frontier (3) exhibits some interesting findings that cannot be seen in the previous analysis. First, Table 3 shows that the elasticity of nonICT capital remains more or less the same level over the whole time period. Meanwhile, there was a decreasing tendency for the elasticity of labour over this time period: it decreased from the level of 0.70 in the late 1970 s to the level of 0.40 in the early 2000s. On the one hand, results from Table 3 clearly provide evidence that ICT capital is an additional type of capital that can provide a significant contribution to growth. On the other hand, it is also worth noting that the elasticity of ICT capital has exhibited a different and interesting pattern: it decreased from the level of 0.20 in the late 1970 s to a relatively low level of 0.15 in the mid of 1980s, and then came back again in 1989. Since then, it has been rapidly increasing.

Hence, it seems that the evidence for the ICT investments from year 1989 onwards is in favour of the ICT-centred story, reflecting the substantial and increasing contributions of the ICT investments to the economic growth. However, the performance of the ICT-capital in the mid of 1980s still puzzled us. Technically, we conjectured that this could be the consequence that an inappropriate log-linear relationship was pre-imposed onto the frontier structure between the output and ICT-capital as an 
input in model (3), which led to an inaccurate measurement of the output elasticity ${ }^{13}$.

This motivates us to move to non-parametric time-specific frontier structure as specified in equation (4), where $f_{1 t}(\cdot), f_{2 t}(\cdot)$, and $f_{3 t}(\cdot)$ are the frontier functions associated with the natural logarithms of non-ICT capital, ICT capital and labour respectively. Note that here the relationship between the output and the ICT-capital as an additional input was estimated without pre-assuming any particular functional form for the underlying production technology. In doing so, we can achieve two objectives simultaneously: (a) to obtain the real impact of ICT capital on economic/productivity growth; and (b) to have a more accurate estimate of technical inefficiency.

The two-level model, equations (4) and (5), was used to fit the data in the analysis and the resulting frontier functions are displayed in Figures 2-4.

We first focus on frontier functions $f_{2 t}($.$) associated with the log ICT capital. The frontier$ functions $f_{2 t}($.$) at the beginning and at the end of the time span under investigation (i.e. years 1977$ and 2005), as well as for years 1985 and 1987, are displayed in Figure 2, where for each graph the horizontal axis displays log ICT capital and the vertical axis displays the corresponding normalized return. Note that the estimated $f_{2 t}($.$) has been normalized to have a zero mean due to the issue of$ identifiability that is common to all additive models. Overall, there is evidence showing that ICT capital is an additional type of capital which can provide a significant contribution to growth over the period of 1977 to 2005.

(Figure 2 is here)

In addition, we have found that the shapes of the frontier functions $f_{2 t}($.$) during years of 1977$ to 1983 and during years of 1991 to 2005 are all similar: they are strictly increasing and close to a straight-line; see, for example, the upper left and lower right graphs of Figure 2 for the frontier

\footnotetext{
${ }^{13}$ The effect of mis-specification of frontier structure has been seen in the literature. For example, Costa and Markellos (1997) found that the so-called "congested area" with a negative slope between inputs and outputs in the London underground from 1970 to 1994 in terms of fleet size and workers (inputs) and millions of train kilometres per year covered by fleet (outputs). Baker (2001), in educational production function analysis, had also found that traditional restrictive specifications fail to capture potential non-linear effects of school resources.
} 
function $f_{2 t}($.$) with t=1977$ and $t=2005$ respectively. The most surprising feature that we have found, however, is that in the mid-1980s, in particular the years from 1984 to 1987, the frontier functions exhibit a J-shape; see for example, the upper right and lower left graphs of the estimated frontier functions $f_{2 t}($.$) for t=1985$ and 1987 respectively. This suggests negative elasticity of ICT capital within some certain range of ICT capital input, i.e. the increment of ICT capital was associated with a decrease of the output. This, to some extent, provides some evidence to support the GPT hypothesis that initially the ICT capital had a negative relationship with productivity.

The results in Figure 2 also provide a satisfactory explanation for the pattern in Table 2 obtained using a linear model (3), where before and after the period of mid-1980s the output elasticity of ICT input maintained an increasing trend, whereas the period of mid-1980s seemed to be an anomaly and the output elasticity was much lower. Figure 2 suggests that the lower output elasticity in the mid1980s was due to the rare nature of ICT as an input: the frontier function of ICT was nonlinear during this certain time period within a certain range of input range.

Although the results in Figure 2 seem to be unexpected to some extents, they are consistent with previous studies like Ketteni et al. (2007) and Ketteni (2009) which have shown that ICT capital has a nonlinear effect on economic and productivity growth. What we also observe from Figure 2 is that prior to the mid/late-1980s, it seems that a 'normal' positive relationship between the output and the input was maintained, indicating that a higher level of the ICT capital led to a higher level of the output. The abnormal relationship exhibited in the mid/late-1980s returned to the norm in the early of 1990s.

It is natural to raise a question whether it is the application of non-parametric model that led to the negative relationship of ICT capital in the transition period in the US. We argue that if this were true, then the return of all three inputs in our model would be likely affected. Annual returns of nonICT and labour displayed in Figures 3-4 show that the returns of the two traditional inputs remained positive and 'normal' as expected. This suggests that the negative relationship of ICT capital in the transition period is unlikely to be due to the use of a non-parametric model. 
(Figure 3 and Figure 4 are here)

\subsubsection{Technical inefficiency}

In general, the component of technical inefficiency $u_{i t}$ represents the effects of the events/factors attributable to the production-unit, such as absorptive capacity, poor management decisions, ineffective communication, worker fatigue, machine obsolescence, and others, on which the production-unit can make efforts to improve. Recent literature has shown that ICT displays many GPT characteristics ${ }^{14}$ and it can be produced in ICT-producing sectors and be dispersed to other sectors of the economy, improving and becoming cheaper over time and facilitating the creation of new goods, services and modes of operation. In this regard, any improvement in inefficiency can be treated as the productivity enhancement in ICT-using sectors due to the spread-over of the general technology produced in ICT-producing sectors.

According to Cardona et al. (2013), despite the fact that TFP regressions provide the clearest and most direct piece of evidence for the GPT theory, the difficulties of undertaking TFP regressions have also been pointed out in the literature because: (a) TFP is highly prone to mis-measurement; and (b) organizational or other forms of intangible capital are usually not measured. As discussed in section 3.1, the traditional growth accounting approach does not consider a number of specific factors influencing growth including adjustment costs, variable factor utilization, deviations from perfect competition and constant returns to scale, management expertise or intangibles that are omitted from official data accounts (Oliner et al., 2008). TFP in the traditional growth accounting approach is simply measured as the total residual in the equation. Given the possible consequence that the TFP would be mis-measured when any of these important factors were not included into the equation, we consider a regression model of technical efficiency against some environmental variables as proxies of organizational or other forms of intangible capital in this paper. This is technically possible because the frontier functions in this research are specified in a nonparametric manner without enforcing any particular structure and hence technical efficiency can be estimated more accurately. In doing so, the

\footnotetext{
${ }^{14}$ To name a few, Bresnahan and Trajtenberg 1995; Basu et al. 2003; Carlaw and Lipsey 2006; Carlaw and Oxley 2008 ; etc. Cardona et al. (2013) provides an excellent review on the connection of ICT and productivity from GPT perspective.
} 
total residual in the traditional growth accounting approach is broken down into individual components that are related to the proxies of organizational or other forms of intangible capital, plus a noise term.

We now consider the details of modelling of inefficiency change in the process of catch-up with an aim to investigating: (a) how technical inefficiency evolved over time; and (b) which factors contributed to the enhancement of technical efficiency. For this end, the evolution of technical inefficiency is linked to the persistency of inefficiency and two exogenous environmental factors software investment and skilled labour, surrogated for ICT infrastructure and the adoptive capacity, respectively. The estimates of the higher level of the two-level model, equation (5), are displayed in table 4.

(Table 4 is here)

It can be seen that the estimate of parameter $\rho$ that characterizes the persistency of technical inefficiency, is 0.44 . It is significant and thus should not be ignored. According to the rule of "survival of the fittest”, firms cannot survive in the long term unless they are technically efficient. However, if technical inefficiency was due to factors that were under the influence of firms themselves but the factors could not be adjusted without costs, then the improvement of efficiency necessarily depends on the cost of adjustment, and a persistent technical inefficiency may appear if such costs are high (Tsionas, 2006). As specified in equation (5), the persistence of the level of inefficiency was captured by $\rho$ with its values ranging from 0 to 1 . Clearly, a coefficient close to 1 indicates that the inefficiency is highly persistent due to high adjustment costs, and therefore there might have little room for the effect of exogenous environmental variables to step in; and vice versa.

With respect to the factors that contributed to the reduction of technical inefficiency, Table 4 shows that both the skilled labour share and software share are negatively related to technical inefficiency, i.e. positively contribute to efficiency improvement in general. The coefficient of the software share is significant at the $5 \%$ level, suggesting that the software share played a crucial role in 
the process of catch-up and efficiency enhancing. However, the coefficient of the skilled labour share, although having an appropriate negative sign, is not significant. One possible reason for this might be that the inappropriate proxy has been chosen - highly-skilled labour is not necessarily equivalent to IT-related staff in reality ${ }^{15}$.

Before concluding this section, we note that according to the GPT theory, a different level of technical inefficiency, before and after the transition period, is expected. In the Bayesian analysis carried out in this research, the hypothesis that average level of technical inefficiency was higher prior to year 1988 than that in the post 1989 era was tested and supported at the 5\% significant level, hence reinforcing the theory of the catch-up process via reorganization.

\subsection{Robustness check}

The empirical analysis in the previous section was based on the US productivity data during years 1977-2005. It is of interest to undertake a robustness check and investigate if the results still hold when we choose a different time period. For this end, we chose the period of 1977-1991 (that includes the transition time period of interest) for robustness analysis and removed the data in the remaining years. The same model, i.e. equations (4)-(5), was used. Overall, the results, as displayed in Figure 5 and Table 5, show similar patterns that we observed earlier, which are summarized as follows:

(a) for the ICT-capital, the frontier functions from years 1984 to 1987 in Figure 5 exhibited a Jshape. This is similar to what were shown in the previous analysis (Figure 2);

(b) for both the non-ICT capital and labour, the results in the robustness analysis (not shown

\footnotetext{
${ }^{15}$ We agree with one reviewer's comment that the insignificant effect of skilled labour has caused some problems in interpreting the results in Table 4. Unfortunately, within the EU-KLEMS database, we were unable to find any useful proxy for reorganization issues at the aggregate (industry) level. This issue can probably be better addressed at a firm-level analysis with a different (firm-level) database.
} 
here) suggest that the returns of the two traditional inputs remained positive and 'normal' as expected, which is similar to what were shown in the previous analysis, Figures 3 and 4;

(c) the results for technical inefficiency in the robustness analysis, as displayed in Table 5, are also in line with what we have seen in Table 4: technical inefficiency exhibited a strong autocorrelation and was negatively affected by software share.

(Figure 5 is here)

(Table 5 is here)

\section{Discussion}

In this research we aim to gain a deeper understanding about the interplay of the different facets of ICT. In particular, we wish to answer the following questions: (1) Of the two existing theories, ICT-centred story and ICT-related story, which theory reveals the truth in the US case? In other words, to what extent the ICT productivity can be attributed to the resurgence growth? (2) What is the role played by organizational complements, through which ICT affects productivity growth? Clearly, addressing these research issues will provide empirical evidence against or in favour of the GPT theory. What we will do now is to look into these issues from an aggregate economic level by bringing all the pieces together.

\subsection{Is ICT a new type of GPT?}

By definition, if ICT were viewed as a new GPT, it should have the features of "pervasiveness, technological dynamism and innovation complementarities” (Bresnahan and Trajtenberg, 1995; Cardona et al. 2013). In other words, within ICT-using industries productivity gains from ICT should 
be observed not only through capital deepening and substitution of inputs of different marginal products but also spillovers across firms/industries occurred through better use of the embodied new technology. Previous literature has investigated these two channels separately, but failed to empirically identify and separate the combined effects and therefore no direct empirical evidence to show that a possible time lag exists. In this end, it is possible that combined ICT productivity effects might be "lagged" over some period of time due to the potential mismatches between the facilitating structure and new technology, and positive ICT productivity effects can only be materialized when the complementaries reached a critical mass of diffusion and experience. Overall, our empirical findings lend support to the view that ICT is a special capital input and are generally in line with the ICT-GPT hypothesis proposed by Carlaw and Lipsey (2006).

After obtaining Figure 2 that shows a J-curve relationship during 1984-1987, we would like to ask what happened during this transition period. The J-curve indicates initial negative relationship between the productivity and the ICT, when the ICT investment was at a relatively low level. That is to say, these high-tech investments were initially counter-productive - they did not provide any visible jump in terms of productivity gains; rather, they had a negative influence on the country/industry's productivity. This can be the case if a country/industry undergoes vigorous reorganizational changes and infrastructure-building before the payoffs from ICT investment were seen ${ }^{16}$; it could also have occurred during some adoptability periods of new ICT investment or even due to inappropriate management of the investment (Basu and Wei, 1998). As a result, a new technology (like ICT) will have an impact on growth that will not be immediately positive but initially cause productivity slowdown, during which period necessary redesigns of physical capital, re-skilling of human capital and changes in the organizational technology of firms, etc. are required following the introduction of a transforming GPT for a time. The variation could even dip and last for a couple of years, as evidenced in Figure 2. Applying our two-level stochastic frontier model, we are able to detect this subtle and interesting structure of the ICT productivity effects.

\footnotetext{
${ }^{16}$ A synthetic survey from Kiley (2001) provides an excellent support for this argument. Specifically, many of them view the adoption of ICT as a technological revolution with substantial short-run negative effects until the new equipment has been completely adapted. In this end, the transition dynamics from a change in technological progress leads to a slowdown in capital accumulation and thus in productivity during the transition period.
} 
Similar findings can be found in the literature although different methodologies are employed. For instance, Hornstein and Krusell (1996) also argued that the coexistence between an increase in technological change due to ICT investment and productivity slowdown might be related to changes in new forms of organization at plant level which are required to obtain the full benefits from ICT, given that average knowledge goes down because relatively more resources are allocated to the new capital. This line of research has been followed by Pakko (2002) and Basu et al. (2001, 2003), arguing that changes in the growth rate of technological progress may not affect productivity contemporaneously, but with a (arbitrary) lag, and factor adjustments implied by technological progress can explain the contemporaneous differences between productivity growth and technological change. All these studies interpreted their findings as indication of the GPT nature of ICT.

The empirical evidence shown in Figure 2 also indicates that this transition period with a negative relationship turned out to be worthwhile: the real productivity slowdown will be turned around and a significant payoff could be delivered over a longer time period when complementary investments were built up and pooled. For instance, the redesign of job practices, the training that workers received, and the realignment of work scope and structure served to bring in a sustained period of high returns. In other words, the relationship of substitutability or complementarity between the inputs varies from one pair of the three inputs (ICT, non-ICT and labour) considered to another, depending on the extent to which the amount of the ICT investment is treated as a low, medium or high level in the organization. At a certain level of ICT investment, ICT stock may better pair with labour than with ordinary capital. Lin and Shao $(2006)^{17}$ found that using ICT capital to replace ordinary capital or ordinary labour or spending more on ICT investments does not necessarily mean more technically (productively) efficient production. However, when looking at the more detailed level, they further showed that non-ICT capital, ICT capital and labour are not pair-wise substitutable. In particular, non-ICT capital and ICT are complementary at the high level of ICT investments while they are substitutable at both the low and medium levels of ICT investment. This finding is also generally consistent with Appropriate Technology Theory proposed by Basu and Wei (1998), i.e. some

\footnotetext{
${ }^{17}$ Equipped with the constant elasticity of substitution stochastic production frontier model.
} 
delayed time frame was needed for the ICT-led development policy to yield returns in the form of significant payoff and improvement. This is because it takes time for ICT usage to be efficiently assimilated into the work force and production lines as the technology matures and the introduction of the GPT ultimately rejuvenates growth before there is a long term productivity benefit. This issue will be further investigated when we address the effect of ICT infrastructure on inefficiency in Section 5.2.

Finally, it is worth noting that the productivity slowdown observed in our J-shaped frontier can also be explained in a wider context in economic literature by use of the "learning-by-doing" concept $^{18}$. Based on the notion of investment-specific technological change, Hornstein and Krusell (1996) hypothesized that once the capital-embodied technological had taken placed, aroused probably by the introduction of new and more powerful computer and/or the invention of more efficient means of telecommunication, a given learning period was generally required during which labour productivity could ultimately be lower than before. Our findings of the positive but lagged effect of ICT on TP is generally line with this proposition. We further note from Figure 2 that it was those industries with lower ICT capital that had productivity problems in the transition time period. This indicates that the productivity problems might be partially attributed to the fact that insufficient ICT inputs were made in those industries and ICT productivity could not be materialized until it reached a critical point. Further research on this issue, ideally at the firm level, needs to be done on this issue.

\subsection{The role of "catch-up"}

The GPT theory and the successive studies viewing ICT as a new GPT suggested that the negative relationship between the productivity and the ICT during the transition period may be due to a process of reorganization associated with ICT investment, the process of which might happen over

\footnotetext{
${ }^{18}$ We thank one of the reviewers for offering us with this alternative explanation, and the conceptual hypothesis of "learningby-doing" has been empirically tested in industries in a broader literature in the productivity slowdown, for example, Benkard (2000) and Ohashi (2005).
} 
the so-called "lagged" period (David 1990; Basu et al. 2003). On the one hand, organizational complements, such as new business processes, new managerial skills and new organizational designs, should be major ICT contributors to productivity growth since one important channel for ICT to affect productivity growth is through its effect on the efficiency of operating methods and working practice. In this regard, firms/industries that adopt organizational restructuring and work practices should achieve a higher level of efficiency, and then a larger contribution of ICT to productivity growth than those that fail to combine ICT investment with appropriate organizational changes. On the other hand, due to "lagged" period, the speed of reorganization for industries using ICT is crucial for policymakers. This can be attributable to two factors: ICT infrastructure and the capability of organization adjustment to digest these ICT investments. (In)efficiency changes, which represent the catch up towards the maximum production potential, are therefore introduced in our framework as a proxy for this speed of reorganization.

The results displayed in Table 4 clearly indicate that the US ICT-using industries were able to adjust organization with moderate costs to digest ICT investment. This finding is generally in line with those previous studies (for example, Brynjolfsson et al. 2002) arguing that certain amount of complementary costs associated with ICT investment are required to accomplish a reorganization process for the potential benefits of the ICT investment being materialized. Basu et al. (2003) further refers these costs as a type of intangible organizational capital.

Existing literature, however, revealed mixed findings with regard to the effect of ICT investment in general, and software investment in particular, on efficiency change. The "organizational computing" was very important for the reduction in both the transaction and management cost for firms in ICT-using industries, which is closely linked with the software itself. For instance, enterprise resource planning, material requirement planning, database management systems and customer resource management were widely used by all sectors of the entire economy. Thus, a high software share in the total ICT infrastructure investment is expected to increase efficiency due to the reduction in relevant costs from the managerial and cost-effectiveness perspective. Moreover, software share can also increase the demand for skilled labour and thus increase efficiency as well (Stiroh, 1998). 
Some researchers, however, argued that IT spending in general did not necessarily improve production efficiency (Lin and Shao, 2006; Lin 2009). We believe that one possible reason for these mixed findings in the previous studies on the efficiency is because the technical efficiency was less likely to be accurately measured when a parametric log-linear frontier such as a Cobb-Douglas was used in the analysis.

Our findings on the positive relationships between high-skilled labour / software share and efficiency improvement are in line with ICT-led development policy that made consistent efforts to provide the necessary infrastructure and an ICT-friendly business environment. Then a significant payoff can be expected to deliver over a longer time period when complementary investments were built up and pooled.

In summary, TFP is highly prone to mis-measurement and organizational or other forms of intangible capital are not measured and therefore not all inputs are observed correctly; it is therefore extremely difficult to find direct evidence to support the GPT theory via the TFP (or its components such as technical efficiency) regressions against these environmental variables (Cardona et al. 2013). In our empirical analysis, we have established an empirical relationship between technical efficiency and two proxies of these intangible variables, thanks to the development of a two-level econometric model, which shed light on the notion of ICT being a GPT.

\section{Conclusions}

Productivity, a key determinant of a nation's wealth and competitiveness in a global market, is of central interest to economists and policy makers - it reflects how effectively inputs, such as labour and capital, are utilized in production process and how effectively are transformed into outputs. While productivity is easy to define, i.e. the amount of outputs produced per unit of inputs, it is notoriously difficult to measure, especially in the modern economy. On the other hand, an associated question here is: where does productivity growth come from? While the greatest increase in productivity has proved to be associated with a particular class of technologies, like the steam engine and electricity setting off a chain of innovation before the 1900 s, the question in $21^{\text {st }}$ century is whether ICT in 
general and computers in particular holds a similar promise in the New Economy.

A voluminous literature has provided abundant evidence on the positive effects of ICT on the structure of economies and the macroeconomic strength in the US can be attributed to rapid productivity growth and be further linked particularly to ICT investment which rose at a rate nearly double that of the preceding years (Jones, 2002 and Jorgenson et al. 2003, etc.). However, many questions surrounding the role of ICT in productivity growth remain unresolved. In particular, a surprising amount of disagreement exists concerning the possible multi-facets of the ICT productivity and the mechanism/channels through which ICT affects productivity growth.

To address these research gaps, this research has focused on: (i) the disentanglement of the sources of ICT-driven productivity growth that have remained puzzling in the previous literature; (ii) the investigation of the channels through which ICT affects productivity growth, both directly and indirectly. By bring all the distinct dimensions of the ICT productivity together into a single unified framework, the two-level stochastic frontier model developed in this paper provides us with an opportunity to gain insights into these issues for the US over the period 1977-2005. On the one hand, the basic-level of the model on the frontier functions estimated via the smoothing spline method enables us to detect the subtle and interesting structure of the ICT frontier function that the existing studies would be unable to discover via the usual frontier structure (e.g. linearity or log-linearity). This has been used to address the issue of direct contribution of ICT to productivity in this paper. On the other hand, based on the more accurately measured inefficiencies, a dynamic equation at the higher level of the developed model is used to investigate how technical inefficiency evolves over time during the time period of interest, and how the inefficiency interacts with the ICT-related factors. This enables us to explore the indirect impact of ICT on productivity.

Our empirical analysis has provided further evidence that ICT capital is a "special" production factor. Like the normal factors, ICT capital positively contributes to productivity growth through the usual way in capital deepening and the input substitution due to more efficient use of inputs. What is more, unlike the normal factors, ICT is strongly linked to innovation and spillovers, reflected by a negative relationship between the output and the log ICT capital over a certain period of time, e.g. 
1984-1987 in the US, possibly due to a potential mismatch between the facilitating structure and embodied technology. In comparison with the previous studies, this paper has contributed to the literature because it has accurately measured the time span of the transition period in the US, estimated the magnitude of the negative impact on the output from the input of ICT capital, and thus provided more solid empirical evidence to support the GPT nature of ICT investment.

In terms of technical efficiency component of productivity growth, our empirical analysis has provided evidence from an aggregate economic level that the proportion of technical efficiency improvement attributed to organizational transformation and production-unit's capacity to learn from the embodied new technology has persistently been enhanced throughout the whole time span of the research. Here, the software share of aggregate ICT investment and highly skilled labour played an important role in the enhancement of efficiency over time. This in turn provides some insights to the observed puzzle that the adoption of ICT-knowledge does require organizational change as suggested by the ICT-related story.

As a whole, we have revealed the unusual J-shaped pattern of ICT frontier function, and established a relationship between technical efficiency and the environmental variables relating to organizational and other forms of intangible investment. These findings provide strong evidence supporting ICT as GPT.

The pattern found and the method developed in this paper can provide new insights for policy makers on ICT investment strategic planning in other countries. Specifically, the findings in this paper suggest that the well-known productivity paradox was indeed an issue in the early stage of ICT development and it applied only to a certain period of time in the mid of 1980s, as in the US case, and a significant payoff to ICT investment could be delivered over a longer time period once complementary investments were built up. In this sense, both the ICT-centred story and ICT-related story have partially revealed the truth: the former reflects the truth in the post-1990s era when the ICT plays a key role in productivity, whereas the latter explains the transition period in the late-1980s. For other developed countries (e.g. other OECD countries apart from the US) and developing countries (e.g. some emerging economies in East Asia and Latin America), we can expect similar patterns in 
terms of ICT investment payoff to some extent, although the exact backdrop years might be longer or shorter depending on these economies’ ICT infrastructure and their capacity to absorb the newlydeveloped technology, etc. 


\section{References}

Baker, B., 2001. Can flexible non-linear modelling tell us anything new about educational productivity? Economics of Education Review 20, 81-92.

Basu, S., Fernald, J., 2007. Information and communications Technology as a general-purpose technology: evidence from US industry data. German Economic Review 8(2),146-173.

Basu, S., Weil, D., 1998. Appropriate technology and growth. The Quarterly Journal of Economics 113(4), 1025-1054.

Basu, S., Fernald, J. G., Outlton, N., Srinivasan, S., 2003. The case of the missing productivity growth. (M. Gertler, \& K. Rogoff, Eds.) NBER Macroeconomics Annual 2003 , 9-63.

Basu, S., Fernald, J., Shapiro, M., 2001. Productivity growth in the 1990s: technology, utiliztion, or adjustment? Carnegie-Rochester Conference Series on Public Policy 55, 117-165.

Becchetti, L, Bedoya, D., Paganetto, L., 2003. ICT investment, productivity and efficiency: evidence at firm level using a stochastic frontier approach. Journal of Productivity Analysis 20, 143-167.

Benkard, C.L., 2000. Learning and forgetting: the dynamics of aircraft production. The American Economic Review 90(4), 1034-1054.

Bresnahan, T., Trajtenberg, M., 1995. General purpose technologies: 'engines of growth'. Journal of Econometrics 65, 83-108.

Bresnahan, T., Brynjolfsson, E., Hitt, L., 2002. Information technology, workplace organization and the demand for skilled labour: firm-level evidence. Quarterly Journal of Economics 117(1), 339-376.

Brynjolfsson, E., 1993. The productivity paradox of information technology. Communications of the ACM 36(12), 66-77.

Brynjolfsson, E., Hitt, L.M., 1996. Paradox lost? Firm-level evidence on the returns to information systems. Management Science 42, 541-558.

Brynjolfsson, E., Hitt, L.M., 2000. Beyond computation: Information technology, organizational transformation, and business performance. Journal of Economic Perspective 14, 23-48.

Brynjolfsson, E., Hitt, L.M., Yang, S., 2002. Intangible assets: Computers and organizational capital. 
Brookings Papers Economic Activity 1, 137-199.

Cardona, M., Kretschmer, T., Strobel, T., 2013. ICT and productivity: conclusions from the emprical literature. Information Economics and Policy 25, 109-125.

Carlaw, K., Lipsey, R., 2002. Externalities, technological complementraries and sustained economic growth. Research Policy 31, 1305-1315.

Carlaw, K., Lipsey, R., 2006. GPT-driven, endogenous growth. Economic Journal 116, 155-174.

Carlaw, K., Oxley, L., 2008. Resolving the productivity paradox. Mathematis and Computers in Simulation 78,313-318.

Caroli, E., van Reenen, J., 2001. Skill-biased organizational change? Evidence from a panel of British and French establishments. Quarterly Journal of Economics 116(4), 1449-1492.

Cohen, W., Levinthal, D., 1989. Innovation and learning: the two faces of R\&D. Economic Journal 99, 569-596.

Colecchia, A., Schreyer, P., 2002. ICT investment and economic growth in the 1990s: is the United States a unique case? A comparative study of nine OECD countries. Review of Economic Dynamics 5, 408-442.

Costa, A., Markellos, R., 1997. Evaluating public transport efficiency with neural network models. Transportation Research C5(5), 301-312.

David, P., 1990. The dynamo and the computer: an historical perspective on the productivity paradox. American Economic Review, Papers and Proceeding 80, 355-361.

Dedrick, J., Gurbaxani, V., \& Kraemer, K., 2003. Information technology and economic performance: a critical review of the empirical evidence. ACM Computing Surveys 35(1), 1-28.

Dewan, S., Kraemer, K., 2000. Information technology and productivity: evidence from country-level data. Mangement Science 46(4), 548-562.

Doms, M., 2004. The boom and bust in infomration technology investment. FRBSF Economics Review 4, 19-34.

Gelman, A., Carlin, J. B., Stern, H. S., Rubin, D. B., 2014. Bayesian data analysis. Chapman \& Hall/CRC.

Gordon, R., 2000. Does the 'New Economy' measure up to the great inventions of the past? Journal of 
Economic Perspectives 14(4), 49-74.

Green, P. J., Silverman, B.W., 1994. Nonparametric Regression and Generalized Linear Models: A Roughness Penalty Approach. London: Chapman \& Hall.

Hajargasht, G., 2004. Some new semiparametric panel stochastic frontiers: A Bayesian penalized approach. Econometric Society 2004 Australasian Meetings.

Hastie, T.J., and Tibshirani, R. J., 1990. Generalized Additive Models. London: Chapman \& Hall.

Helpman, E., (1998). General Puurpose Technologies and Economic Growth. Cambridge: MIT Press.

Hornstein, A., Krusell, P., 1996. Can technology improvements cause productivity slowdowns? NBER Macoeconomics Annual 209-259.

Inklaar, R., O'Mahony, M., Timmer, M., 2005. ICT and Europe's productivity performance: industrylevel growth account comparisons with the United States. Review of Income and Wealth 51(4), 505-536.

Jones, C., 2002. Introdution to Economic Growth. New York: W.W.Norton \& Company, Inc.

Jorgenson, D., Stiroh, K., 2000. Raising the speed limit: US economic growth in the information age. Brookings Papers on Economic Activity 1, 125-211.

Jorgenson, D., Ho, M., Stiroh, K., 2008. A Retrospective look at the US productivity growth resurgence. Journal of Economic Perspectives 22(1), 3-24.

Jorgenson, D., Ho, M., Stiroh, K., 2003. Growth of US indistries and investments in information technology and higher education. Economic System Research 15(3), 279-325.

Ketteni, E., 2009. Information technology and economic performance in U.S industries. Canadian Journal of Economics 42(3), 844-865.

Ketteni, E., Mamuneas, T.P., Stengos, T., 2007. Nonlinearities in economics growth: a semiparametric approach applied to information technology data. Journal of Macroeconomics 29, 555-568.

Kiley, M., 2001. Computers and growth with frictions: affregate and disaggregate evidence. CarnegieRochester Conference Series on Public Policy 55, 171-215.

Kleis, L., Chwelos, P., Ramirez, R.V., Cockburn, I., 2011. Information technology and intangible output: the impact of IT investment on innovation productivity. Information Systems Research, 23(1), 42-59. 
Koop, G., Osiewalski, J., Steel, M., 2000. Modelling the sources of output growth in a panel of countries. Journal of Business \& Economic Statistics 18(3), 284-299.

Koop, G., Osiewalski, J., Steel, M., 1999. The components of output growth: a stochastic frontier analysis. Oxford bulletin of Economics and Statistics 61(4), 455-487.

Lin, W., 2009. The business value of information technology as measured by technical efficiency: evidence from country-level data. Decision Support Systems 46(4), 865-874.

Lin, W., Shao, B., 2006. The business value of information technology and inputs substitution: the productivity paradox revisited. Decision Support Systems 42, 493-507.

Lipsey, R.G., Carlaw, K.I., Bekar, C., 2005. Economic Transformations: General Purpose Technologies, and Long Term Economic Growth. Oxford: Oxford University Press.

McGuckin, R.H., Stiroh, K.J., 2002. Computers and productivity: are aggregation effects important? Economic Inquiry 40(1), 42-59.

Ohashi, H., 2005. Learning by doing, export subsidies, and industry growth: Japanese steel in the 1950s and 1960s. Journal of International Economics 66, 297-323.

Oliner, S. D. , Sichel, D.E., Stiroh, K.J., 2008. Explainging a productivity decade. Journal of Policy Modeling 30, 633-673.

Oliner, S., Sichel, D., 2002. Information technology and productivity: where are we now and where are we going? Federal Researve Bank of Atlanta Economic Review 87, 15-44.

Oliner, S., Sichel, D., 2000. The resurgence of growth in the late 1990s: is the information technology the story? Journal of Economic Perspectives 14(4), 3-22.

O’Mahony, M., Timmer, M., 2009. Output, input and productivity measures at the industry level: the EU KLEMS database. The Economic Journal 119, 374-403.

Pakko, M.R., 2002. What happens when the technology growth trend changes? Transitioin dynamics, capital growth and the “new economy”. Review of Economic Dynamics 5, 376-407.

Stiroh, K., 1998. Computers productivity and input substitution. Economic Inquiry 36(2), 175-191.

Stiroh, K., Botsch, M., 2007. Information technology and productivity growth in the 2000s. German Economic Review 8(5), 255-280.

Timmer, M., O'Mahony, M., van Ark, B., 2007. Growth and productivity accounts from EU KLEMS: 
an overview. National Institute Economic Review 200, 64-78.

Tsionas, E., 2006. Inference in dynamic stochastic frontier models. Journal of Applied Econometrics 21(5), 669-676.

Vu, K.M., 2013. Information and Communication Technology (ICT) and Singapore's economic growth. Information Economics and Policy 25, 284-300.

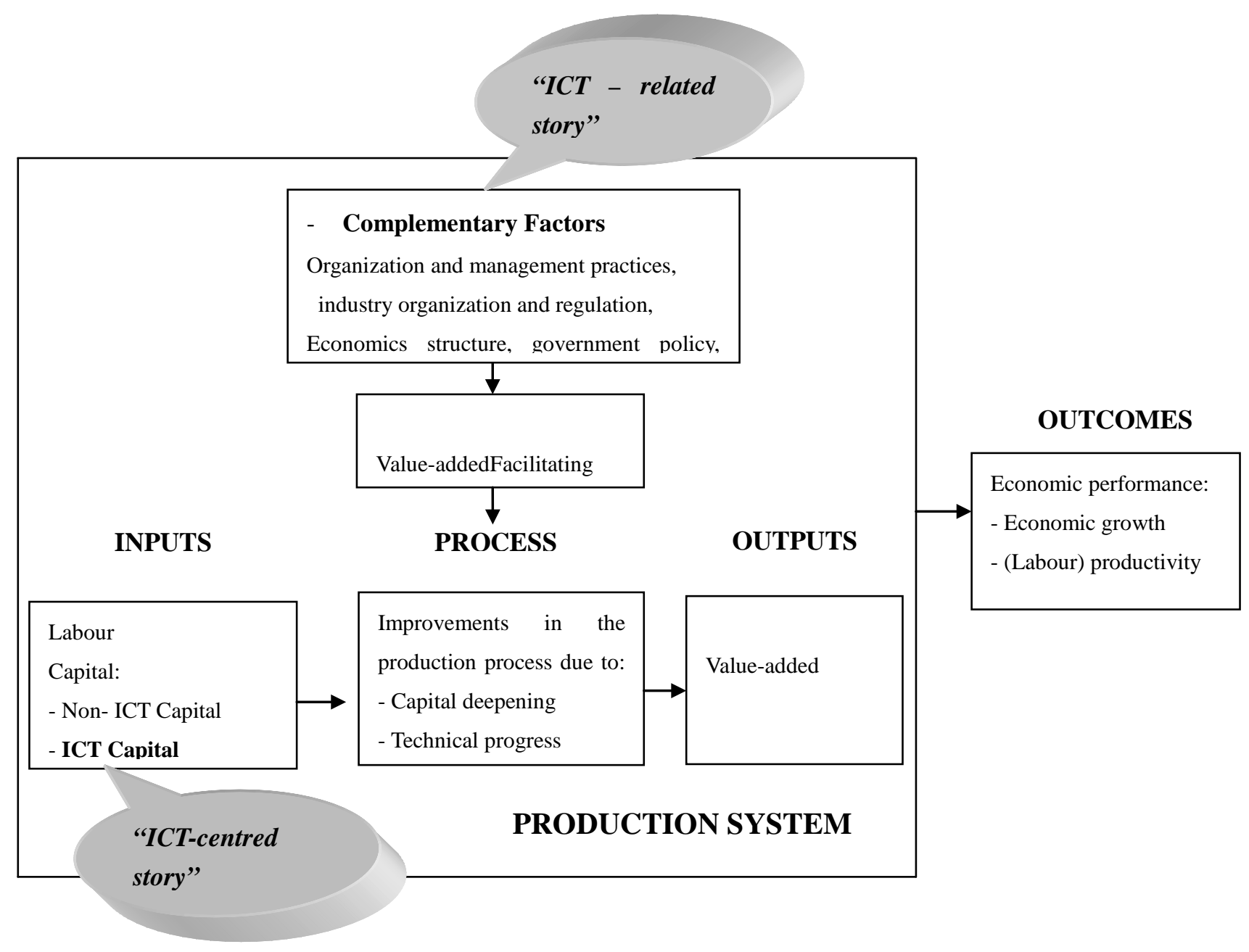

Figure $1 \quad$ Framework for ICT and performance 

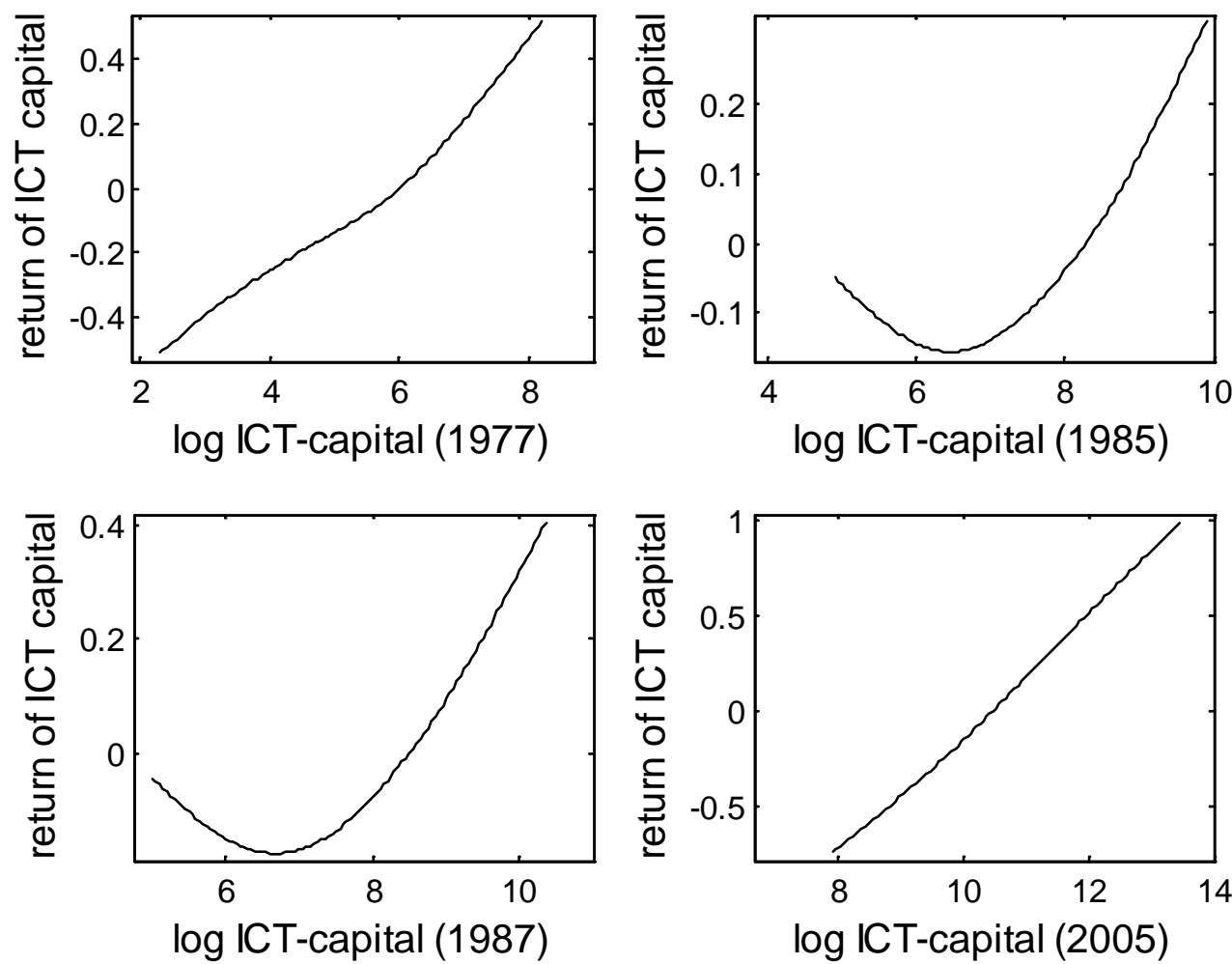

Figure 2 Non-parametric estimates of the frontier functions $f_{2 t}($.

Notes:

- For the normalized return of ICT capital for years $t=1977$ (upper left), 1985 (upper right), 1987 (lower left) and 2005 (lower right), respectively.

- For each graph the horizontal axis displays log ICT capital and the vertical axis displays the corresponding normalized return. Note that the shapes of the frontier functions $f_{2 t}($.$) during years of 1977$ to 1983 and during years 1991 to 2005 are all similar in the sense that the frontier functions are strictly increasing and close to a straight-line (shown only for years 1977 and 2005 here). The frontier functions $f_{2 t}($.$) during the$ transition period of 1984 to 1990, however, are not monotonic, as illustrated for years 1985 and 1987. 


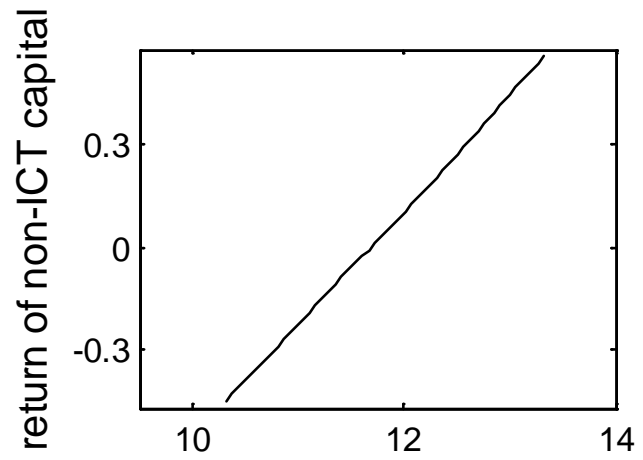

log non-ICT-capital (1977)

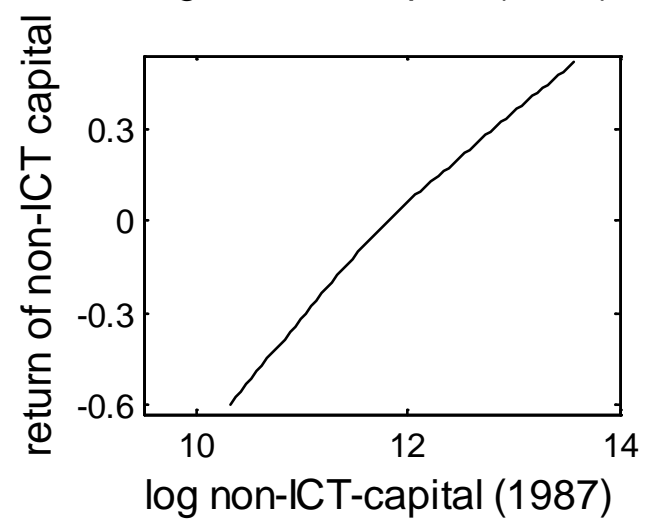

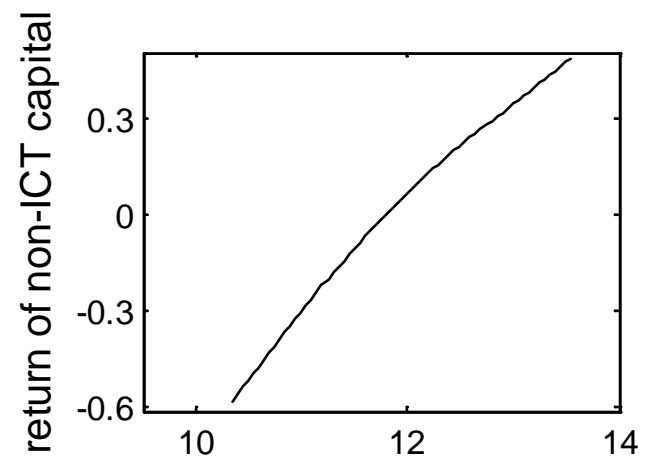

log non-ICT-capital (1985)

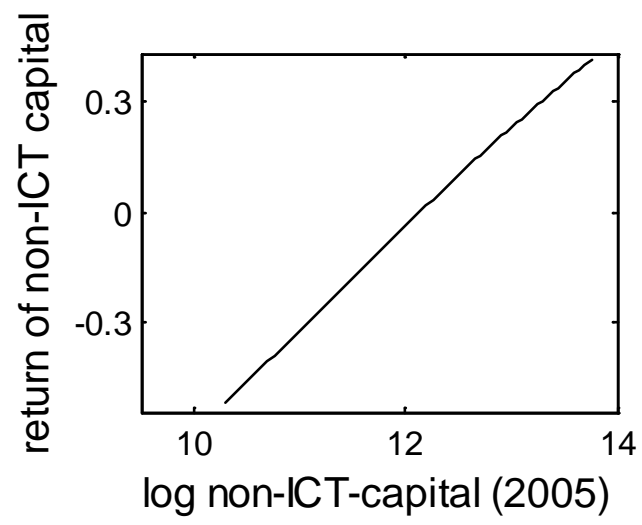

Figure 3 Non-parametric estimates of the frontier functions $f_{1 t}($.

Notes:

- For the normalized return of non-ICT capital for years $t=1977$ (upper left), 1985 (upper right), 1987 (lower left) and 2005 (lower right), respectively.

- For each graph the horizontal axis displays log non-ICT capital and the vertical axis displays the corresponding normalized return. Note that the shapes of the frontier functions $f_{1 t}($.$) during years of 1977$ to 2005 are all strictly increasing and close to a straight-line (shown only for years 1977, 1985, 1987 and 2005 here). 

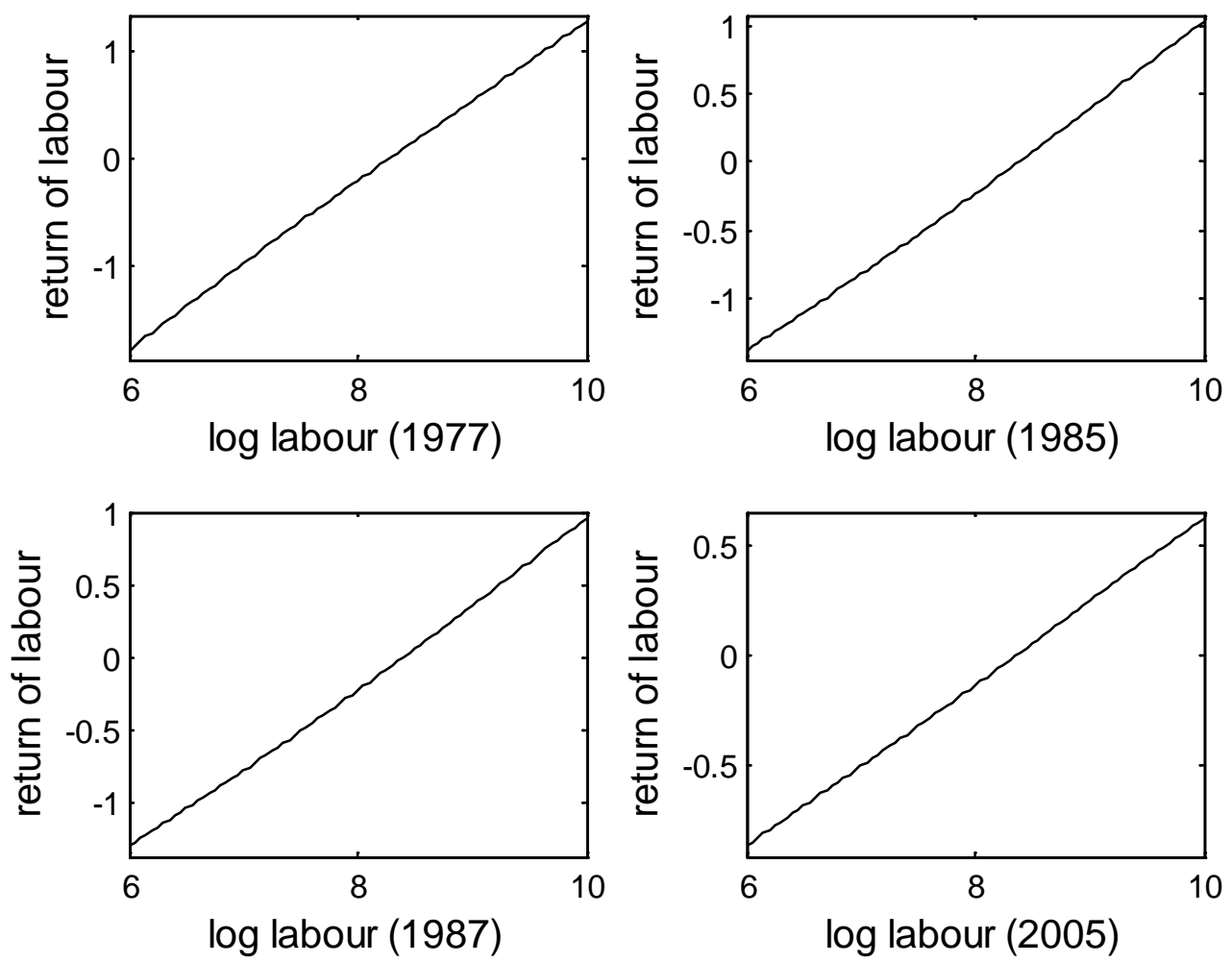

Figure 4 Non-parametric estimates of the frontier functions $f_{3 t}($.

Notes:

- For the normalized return of labour for years $t=1977$ (upper left), 1985 (upper right), 1987 (lower left) and 2005 (lower right), respectively.

- For each graph the horizontal axis displays log labour and the vertical axis displays the corresponding normalized return. Note that the shapes of the frontier functions $f_{3 t}($.$) during years of 1977$ to 2005 are all strictly increasing and close to a straight-line (shown only for years 1977, 1985, 1987 and 2005 here). 

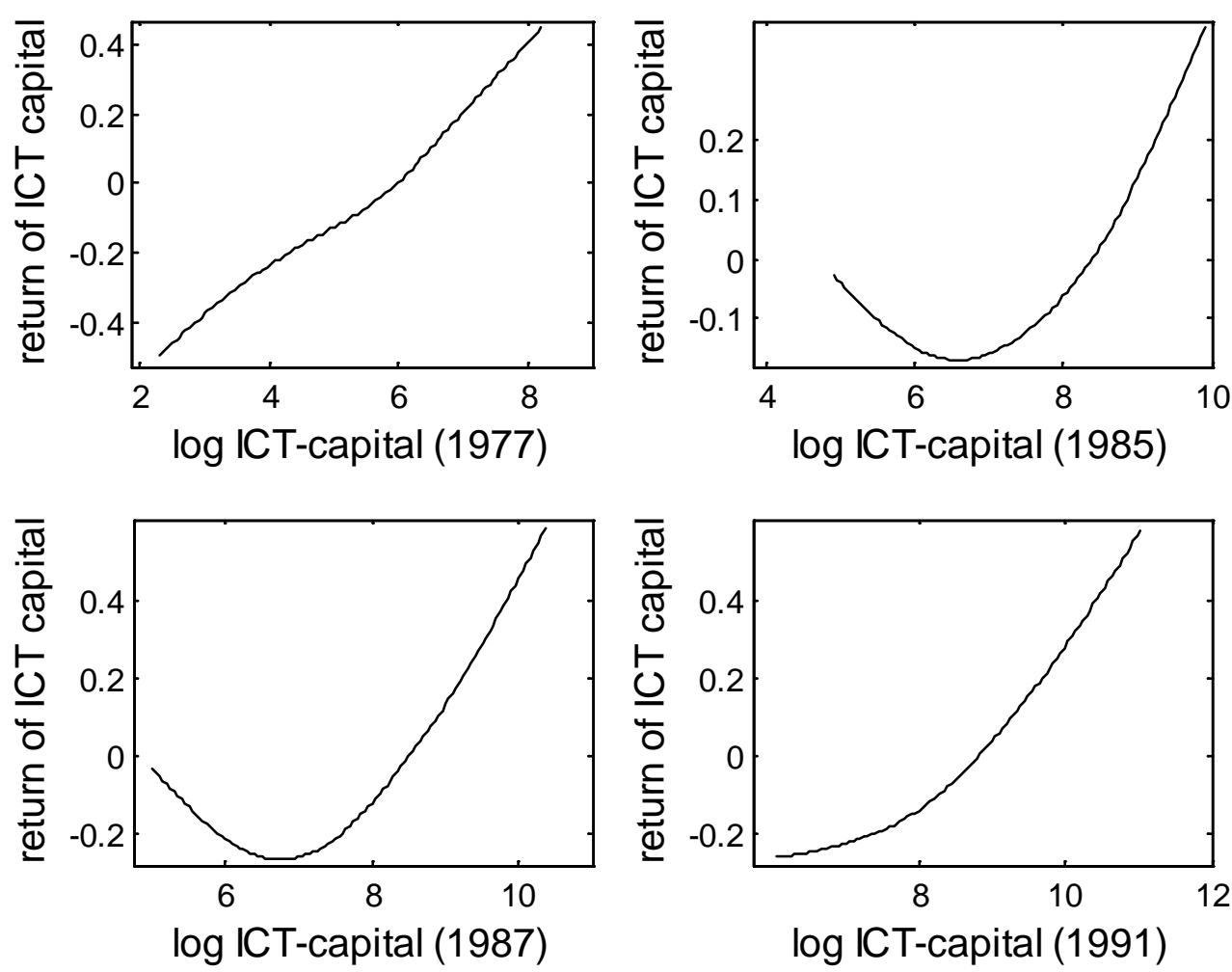

Figure 5 Robustness check

Notes:

- It is based on the data in the period of 1977 to 1991.

- Non-parametric estimates of the frontier functions $f_{2 t}($.$) for the normalized return of ICT capital for years$ $t=1977$ (upper left), 1985 (upper right), 1987 (lower left) and 1991 (lower right), respectively.

- For each graph the horizontal axis displays log ICT capital and the vertical axis displays the corresponding normalized return. Note that the shapes of the frontier functions $f_{2 t}($.$) during years of 1977$ to 1983 are all strictly increasing and close to a straight-line (shown only for year 1977 here). The frontier functions $f_{2 t}($. during the transition period of 1984 to 1990, however, are not monotonic, as illustrated for years 1985 and 1987. 
Table 1 Descriptive statistics for panel data of the US (1977 to 2005)

\begin{tabular}{lrrrr}
\hline Variables & Mean & Std dev & Minimum & Maximum \\
\hline Output (millions of \$) & 170,398 & 163,636 & 8,879 & $1,072,157$ \\
Labour(millions hours) & 6,667 & 6,206 & 279 & 33,874 \\
Non-ICT capital (millions of \$) & 229,966 & 211,923 & 28,578 & 975,073 \\
ICT capital (millions of \$) & 23,267 & 67,368 & 10 & 728,755 \\
Skilled labour (\%) & 18.7 & 10.0 & 4.5 & 48.6 \\
Software share (\%) & 39.6 & 18.5 & 3.5 & 97.6 \\
\hline Sample counts & \multicolumn{4}{c}{696} \\
\hline
\end{tabular}

Table 2 Output elasticities of inputs estimated from time-invariant log-linear function (2)

\begin{tabular}{ccc}
\hline Non-ICT capital & ICT capital & Labour \\
\hline $0.18^{*}(0.02)$ & $0.16^{*}(0.01)$ & $0.60 *(0.01)$
\end{tabular}

Note: (i) Posterior means and posterior standard deviations in parentheses.

(ii) * indicates $p<0.05$. 
Table 3 Output elasticities of inputs estimated from a time-specific linear model

\begin{tabular}{|c|c|c|c|c|c|c|c|}
\hline Year & Non-ICT & ICT & Labour & Year & Non-ICT & ICT & Labour \\
\hline 1977 & $0.18(0.10)$ & $0.19 *(0.05)$ & $0.69 *(0.10)$ & 1992 & $0.14 *(0.07)$ & $0.24 *(0.06)$ & $0.57 *(0.06)$ \\
\hline 1978 & $0.14(0.10)$ & $0.20 *(0.06)$ & $0.75 *(0.10)$ & 1993 & $0.12(0.07)$ & $0.30 *(0.06)$ & $0.50 *(0.06)$ \\
\hline 1979 & $0.10(0.10)$ & $0.20 *(0.06)$ & $0.73 *(0.09)$ & 1994 & $0.15 *(0.07)$ & $0.29 *(0.06)$ & $0.49 *(0.06)$ \\
\hline 1980 & $0.09(0.10)$ & $0.19 *(0.06)$ & $0.77 *(0.09)$ & 1995 & $0.14 *(0.06)$ & $0.31 *(0.05)$ & $0.48 *(0.05)$ \\
\hline 1981 & $0.09(0.10)$ & $0.17 *(0.06)$ & $0.72 *(0.09)$ & 1996 & $0.15 *(0.07)$ & $0.31 *(0.05)$ & $0.45 *(0.05)$ \\
\hline 1982 & $0.10(0.11)$ & $0.15 *(0.06)$ & $0.75 *(0.09)$ & 1997 & $0.16 *(0.07)$ & $0.30 *(0.06)$ & $0.44 *(0.06)$ \\
\hline 1983 & $0.03(0.10)$ & $0.20 *(0.06)$ & $0.67 *(0.09)$ & 1998 & $0.16 *(0.07)$ & $0.31 *(0.06)$ & $0.42 *(0.06)$ \\
\hline 1984 & $0.08(0.10)$ & $0.17 *(0.06)$ & $0.66 *(0.08)$ & 1999 & $0.18 *(0.07)$ & $0.31 *(0.06)$ & $0.41 *(0.06)$ \\
\hline 1985 & $0.12(0.10)$ & $0.14 *(0.06)$ & $0.65 *(0.08)$ & 2000 & $0.19 *(0.07)$ & $0.29 *(0.05)$ & $0.44 *(0.06)$ \\
\hline 1986 & $0.12(0.09)$ & $0.14 *(0.05)$ & $0.69 *(0.08)$ & 2001 & $0.17 *(0.08)$ & $0.30 *(0.06)$ & $0.47 *(0.06)$ \\
\hline 1987 & $0.14(0.10)$ & $0.15 *(0.06)$ & $0.60 *(0.08)$ & 2002 & $0.16 *(0.08)$ & $0.32 *(0.06)$ & $0.42 *(0.06)$ \\
\hline 1988 & $0.11(0.09)$ & $0.19 *(0.06)$ & $0.57 *(0.08)$ & 2003 & $0.16 *(0.08)$ & $0.32 *(0.06)$ & $0.42 *(0.06)$ \\
\hline 1989 & $0.11(0.09)$ & $0.20 *(0.06)$ & $0.56 *(0.07)$ & 2004 & $0.14(0.08)$ & $0.34 *(0.06)$ & $0.39 *(0.06)$ \\
\hline 1990 & $0.13(0.08)$ & $0.21 *(0.06)$ & $0.61 *(0.07)$ & 2005 & $0.12(0.08)$ & $0.34 *(0.06)$ & $0.43 *(0.06)$ \\
\hline 1991 & $0.14(0.08)$ & $0.23 *(0.06)$ & $0.58 *(0.07)$ & & & & \\
\hline
\end{tabular}

Note: (i) Posterior means and posterior standard deviations in parentheses. (ii) * indicates $p<0.05$.

Table 4 Estimates of the coefficients in equation (5) for the US productivity obtained using the data during 1977-2005

\begin{tabular}{ccc}
\hline $\begin{array}{c}\text { AR lag } 1 \text { of technical } \\
\text { inefficiency }\end{array}$ & $\begin{array}{c}\text { Highly skilled } \\
\text { labour share }\end{array}$ & Software share \\
\hline $0.44 *(0.04)$ & $-0.16(0.12)$ & $-0.48 *(0.12)$ \\
\hline
\end{tabular}

Note: (i) Posterior means and posterior standard deviations in parentheses. (ii) * indicates $p<0.05$.

Table 5 Estimates of the coefficients in equation (5) for the US productivity obtained using the data during 1977-1991

\begin{tabular}{ccc}
\hline $\begin{array}{c}\text { AR lag } 1 \text { of technical } \\
\text { inefficiency }\end{array}$ & $\begin{array}{c}\text { Highly skilled } \\
\text { labour share }\end{array}$ & Software share \\
\hline $0.50 *(0.05)$ & $-0.19(0.17)$ & $-0.30 *(0.14)$ \\
\hline
\end{tabular}

Note: (i) Posterior means and posterior standard deviations in parentheses. (ii) * indicates $p<0.05$. 


\section{Appendix}

Table A.1 SIC classification of 24 ICT-using industries

\begin{tabular}{|c|c|}
\hline Industries & Code \\
\hline MARKET SERVICES, EXCLUDING POST AND TELECOMMUNICATIONS & MSERV \\
\hline Sale and repair of motor vehicles and motorcycles; retail sale of fuel & 50 \\
\hline Wholesale trade and commission trade & 51 \\
\hline Retail trade, except of motor vehicles and motorcycles & 52 \\
\hline Transport and storage & $60 t 63$ \\
\hline Financial intermediation & $\mathrm{J}$ \\
\hline Renting of machinery and equipment and other business activities & $71 \mathrm{t74}$ \\
\hline Hotels and restaurants & $\mathrm{H}$ \\
\hline Other community, social and personal services & $\mathrm{O}$ \\
\hline GOODS PRODUCING, EXCLUDING ELECTRICAL MACHINERY & GOODS \\
\hline Food products, beverages and tobacco & $15 \mathrm{t} 16$ \\
\hline Textiles, textile products, leather and footwear & $17 \mathrm{t} 19$ \\
\hline Manufacturing; recycling & $36 \mathrm{t} 37$ \\
\hline Wood and products of wood and cork & 20 \\
\hline Pulp, paper, paper products, printing and publishing & $21 \mathrm{t} 22$ \\
\hline Coke, refined petroleum products and nuclear fuel & 23 \\
\hline Chemicals and chemical products & 24 \\
\hline Rubber and plastics products & 25 \\
\hline Other non-metallic mineral products & 26 \\
\hline Basic metals and fabricated metal products & $27 \mathrm{t} 28$ \\
\hline Machinery & 29 \\
\hline Transport equipment & $34 \mathrm{t} 35$ \\
\hline Mining and quarrying & $\mathrm{C}$ \\
\hline Electricity, gas and water supplies & $\mathrm{E}$ \\
\hline Construction & $\mathrm{F}$ \\
\hline Agriculture, hunting, forestry and fishing & $\mathrm{AtB}$ \\
\hline
\end{tabular}

\footnotetext{
i Corresponding author. Email: hailin.liao@coventry.ac.uk or ab8576@coventry.ac.uk. Tel: +44 (0)24 77657907. School of Economics, Finance and Accounting, Faculty of Business and Law, Coventry University, Coventry, United Kingdom. CV1 5FB.
} 